Article

\title{
Research on Safety Regulation of Chemical Enterprise under Third-Party Mechanism: An Evolutionary Approach
}

\author{
Xing Xin \\ School of Economics and Management, Wuhan University, Wuhan 430072, China; xinxing898@163.com; \\ Tel.: +86-186-3715-1332
}

Received: 21 July 2019; Accepted: 15 August 2019; Published: 16 August 2019

\begin{abstract}
In recent years, China's chemical industry has incurred frequent safety accidents which seriously impact the social environment and public safety. Traditional approaches have reached a bottleneck due to a lack of relevant professionals in the government regulation of chemical enterprise safety production. Thus, a new safety regulation mechanism should be conducted. In this paper, we constructed an evolutionary game model of chemical industry safety regulation based on limited rationality, and the influence of main parameters on the equilibrium evolution process is studied by system dynamics simulation. The results show that government regulation authorities play a leading role in the process of chemical industry safety regulation and increasing punishment will help to achieve an evolutionary stable strategy (ESS). What is more, the feasibility and effectiveness of the third-party regulation service mechanism are verified, and the market access threshold of third-party regulation service needs to be improved to stop the occurrence of rent-seeking activities in the regulatory process. In summary, the introduction of third-party regulation service entities to the chemical industry safety regulation process has far-reaching implications for promoting the healthy development of China's chemical industry.
\end{abstract}

Keywords: chemical enterprise safety regulation; third-party regulation service; evolutionary game; system dynamics

\section{Introduction}

Since the reform and opening up, China's chemical industry has achieved great progress. The industrial layout and supporting facilities are continuously improving, and integrated competitive advantages are frequently emerging, occupying an increasingly important position in the global chemical industry. In recent years, changes have taken place in the global chemical industry pattern in 2002 and 2015, and the proportion of China's chemical output value has increased (Figure 1). At the same time, the proportion of sales of chemical products in China is also mounting. According to Chemdata's report [1], sales of global chemicals in 2016 were 336 billion euros; sales of chemicals in China were 133.1 billion euros, accounting for $64.37 \%$ of the sales of chemicals in Asia and $39.6 \%$ of the world's chemical sales. Now, China is the world's largest chemical sales country. The geographical distribution of global chemical sales in 2016 is shown in Figure 2.

Safe production is a prerequisite for the production and operation of enterprises. Only by ensuring safety can we create greater economic and social benefits. Safety production of chemical enterprises is closely related to the safety of people's lives, property and social stability. With the continuous development of China's chemical industry, bottlenecks such as safety management are becoming more and more prominent [2]. Due to the increasingly complex production process and the expanding production scale of chemical enterprises, the production process is becoming more cumbersome, as is 
the strictness of equipment operating conditions. Most chemical products are flammable, explosive, poisonous and radioactive, and there are large-scale production processes in chemical enterprises. Safety risks are prone to cause major safety incidents leading to serious casualties, property damage and environmental pollution [3,4]. In recent years, there have been frequent chemical accidents in China [5]. For example, on 21 March 2019, an explosion happened in Jiangsu Yancheng Xiangshui Tianjiayi Chemical Co., Ltd., killing 78 people and injuring 566 people. The summary of major accidents in China's chemical industry during 2010 and 2019 is shown in Table 1.
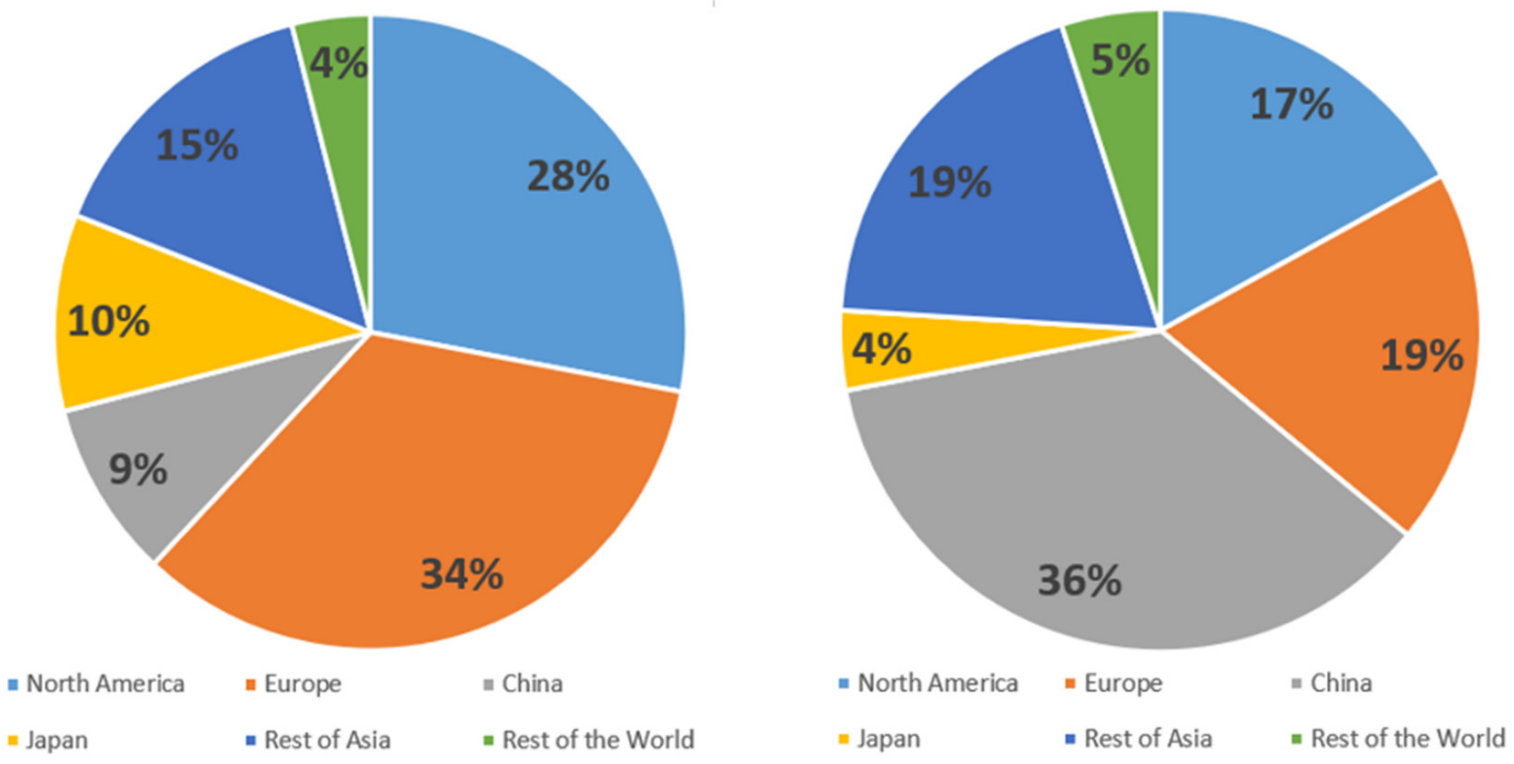

Figure 1. Changes in the pattern of the global chemical industry in 2002 and 2015. Data Sources: Cefic Chemdata's International Report [1]

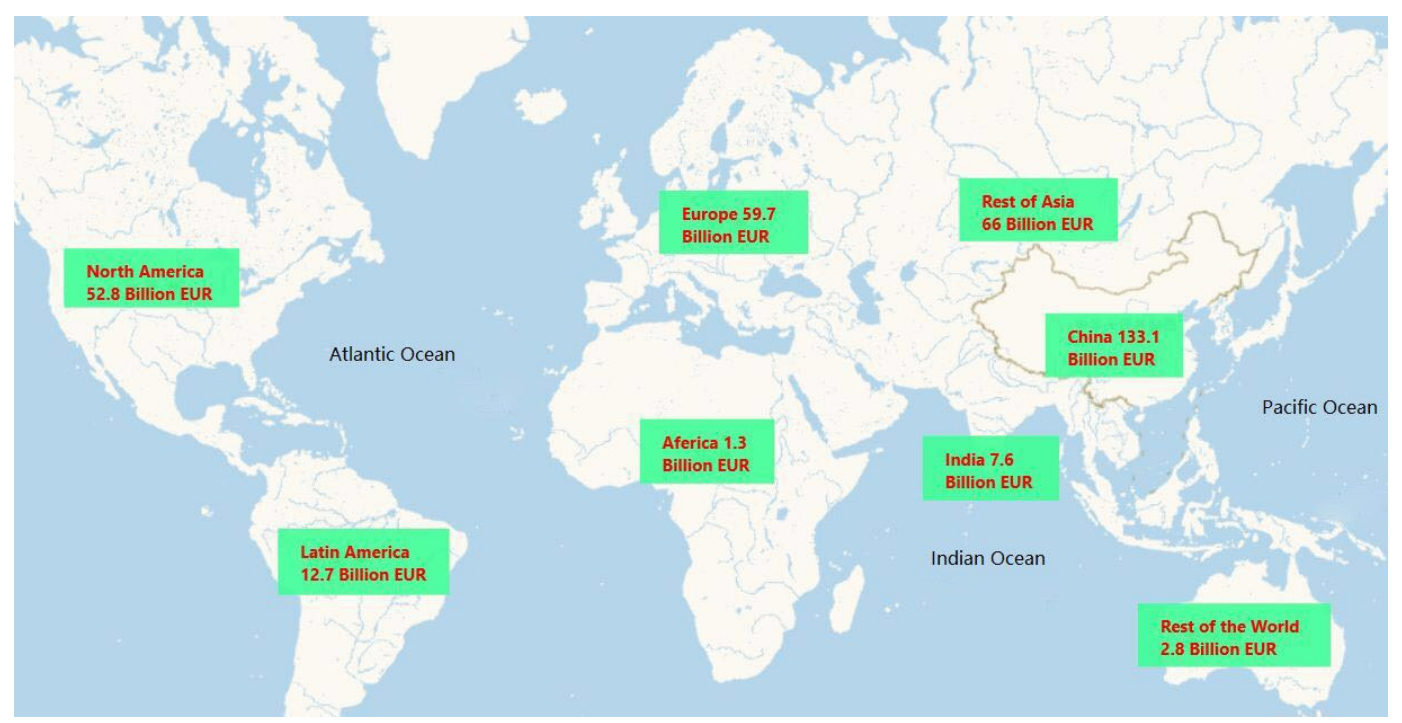

Figure 2. Geographical distribution of global chemical sales in 2016. Data Sources: Cefic Chemdata's International Report [1] 
Table 1. Summary of major accidents in China's chemical industry from 2010 to 2019.

\begin{tabular}{|c|c|c|}
\hline Date (Year.Month.Day) & Accident & Casualties \\
\hline 2010.7.28 & $\begin{array}{c}\text { Jiangsu Nanjing factory blast accident: } \\
\text { leakage and deflagration of } \\
\text { underground propylene pipeline }\end{array}$ & 13 people died and 120 injured \\
\hline 2012.2.28 & $\begin{array}{l}\text { Hebei Zhaoxian Kerr Chemical } \\
\text { Company workshop explosion }\end{array}$ & 29 people died and 46 injured \\
\hline 2013.11.22 & $\begin{array}{l}\text { Shandong Qingdao Huanghua oil } \\
\text { pipeline explosion }\end{array}$ & 72 people died and 156 injured \\
\hline 2015.8.12 & $\begin{array}{l}\text { Tianjin port area Ruihai Company } \\
\text { Chemical warehouse explosion }\end{array}$ & 173 people died and 798 injured \\
\hline 2017.6 .5 & $\begin{array}{l}\text { Shandong Linyi Jinyu Petrochemical } \\
\text { Company explosion }\end{array}$ & 10 people died and 9 injured \\
\hline 2018.7.12 & $\begin{array}{l}\text { Sichuan Yibin Hengda Technology } \\
\text { Company explosion }\end{array}$ & 19 people died and 12 injured \\
\hline 2018.11.28 & $\begin{array}{l}\text { Hebei Zhangijakou Shenghua } \\
\text { Chemical Company deflagration }\end{array}$ & 23 people died and 22 injured \\
\hline 2019.3.21 & $\begin{array}{l}\text { Jiangsu Xiangshui Tianjiayi Company } \\
\text { "3.21" explosion }\end{array}$ & 78 people died and 566 injured \\
\hline
\end{tabular}

Compared with other industries, the production process of chemical enterprises has inherent high-risk attributes. However, as long as regulation and management work are done properly, the hidden dangers are preventable and controllable. Accidents frequently indicate that the current government regulation is not strict enough, the regulation effect is not satisfactory, and sufficient safety investment and management are not in place [6]. Therefore, the flawed safety production regulation mechanism is a key reason for the frequent occurrence of safety accidents in chemical enterprises [7]. In recent years, the Chinese government has attached high importance to the safety production of chemical enterprises. In order to strengthen safety production, prevent and reduce production safety accidents, and promote sustained and healthy economic and social development, it implemented the "Safety Production Law of the People's Republic of China" on 1 December 2014, which requires local safety production regulation departments to carry out comprehensive regulation of safety production work. After the "3.21" explosion accident in Xiangshui, Jiangsu on 1 March 2019, the State Council issued the "Emergency Regulations for Production Safety Accidents" to further standardize production safety regulations, curb the occurrence of safety accidents, and reduce casualties. Chemical enterprises are basic industries. It is necessary to improve the effectiveness of government regulation in the production process of chemical enterprises, strengthen regulation and control, and improve the safety production reward and punishment mechanisms for chemical enterprises. It is also important to ensure national security and promote the healthy development of chemical enterprises.

After sorting out chemical accidents in the past, it is not difficult to find that there are two main reasons for chemical accidents. First, the internal safety management of chemical enterprises is not in place. Second, the external safety regulation of the government is not strict [8]. In addition, given the professional safety inspection in the chemical production process, professionals and technical teams are required to identify problems and solve them. However, as of 2019, while there are more than 200,000 chemical enterprises in the country, only $\sim 4000$ people are supervisors with chemical backgrounds; this indicates a serious shortage of professionals. Therefore, the safety production of chemical enterprises requires that government regulation departments not only strengthen the regulation of chemical enterprises, but also penalize those violating laws and regulations. It is also incumbent to strengthen professional regulation, introduce third-party regulation service mechanisms in the form of purchasing services, and improve the efficiency of government regulation. 
Based on the above analysis, it can be seen that the government regulation of chemical enterprise safety production is the result of strategic interaction between government regulation authorities, chemical enterprises, and third-party regulation service agencies. The effectiveness of government regulation depends on scientific institutional design. When government regulation authorities regulate the production behavior of chemical enterprises through the punishment mechanism and purchase third-party regulation services, they must consider the impact of regulatory costs. At the same time, chemical enterprises and third-party regulation service agencies will also dynamically adjust their strategic selections, their influence on each other, and the symbiotic evolution according to the principle of profit maximization. Thus, it is of great significance to study the strategic interaction and co-evolution between government and chemical enterprises under third-party regulation. Based on bounded rationality, we constructed a three-party evolutionary game model between government regulation agencies, chemical enterprises, and third-party regulation service agencies, and validated the effectiveness of the penalty mechanism by means of simulation analysis. What is more, the efficiency of introducing the third-party regulation service mechanism into the chemical enterprise safety regulation can be proved by simultaneously reducing the government's safety regulation cost and enhancing chemical enterprise production safety.

The rest of this paper is organized as follows: Section 2 provides a comprehensive review of the relevant literature on safety oversight. Section 3 constructs an evolutionary game model for the safety production regulation of chemical enterprises under the regulation of third parties. Section 4 builds the corresponding system dynamics model based on the replication dynamic equation and performs corresponding simulation analysis. Section 5 summarizes the research findings and proposes corresponding policies.

\section{Literature Review}

Safety and risk management is such a critical and central activity [8] that it is necessary to effectively and efficiently implement occupational safety and health management systems $[9,10]$. At the same time, it is also very important to strengthen government regulations. Government regulation is an important factor to prevent the frequent occurrence of chemical accidents. In recent years, some scholars have studied the causes, characteristics, and laws of chemical safety accidents [11,12]. The occurrence of safety accidents in chemical enterprises is closely related to the lack of strict regulation and insufficient investment in corporate safety. Due to information asymmetry and negative externalities of safety incidents, to name a few, it is necessary for the government to strengthen safety regulation measures to guide enterprises in controlling risks, reducing irrational behavior, and improving safety performance [13-15]. Wachter et al. [16] analyzed the impact of enterprise safety production regulation and management on employee behavior from the perspective of internal enterprise safety management and proposed that the implementation of a production safety management information system can effectively reduce accident rates. Makin and Winder [17] discussed the impact of the external environment on the safety production of enterprises and proposed that government regulation can improve the effectiveness of safety production efficiency. Clemons and Madhani [18] also analyzed the need for government regulation in terms of regulatory costs, strengths, and approaches. Smith et al. [19] pointed out that the government and enterprises need to strengthen safety training and guidance for employees engaged in hazardous work and enhance employees' safety awareness, thereby improving the safety management level of enterprises and preventing the occurrence of safety accidents. Therefore, in order to avoid chemical production safety accidents, the Chinese government urgently needs to strengthen the safety regulation of chemical enterprises.

However, there are certain limitations in the current government regulation in China. From the perspective of the government regulation system, Cadman and Tim [20] pointed out problems with government regulation, such as low regulation efficiency, insufficient regulation power, and unclear regulatory responsibilities. At the same time, the large number of enterprises, the wide scope of regulation, and the limited regulatory resources will ultimately lead to regulatory dilemmas for 
government regulation agencies. Therefore, some scholars have proposed to improve government regulation by establishing a third-party regulation mechanism that makes up for the limitations of government regulation [21-23]. Third-party regulation is conducive to improving the status quo of enterprise safety management and improving government regulatory efficiency [24]. In the process of enterprise production regulation, the three important agents are: government regulation agencies, manufacturing enterprises, and third-party institutions [25]. Thus, establishing a third-party regulation mechanism is of great significance to give full play to the advantages of the third-party's technology and resources, to solve the problem of poor government regulation, and to improve the safety production regulation of chemical enterprises.

The safety production of chemical enterprises involves multiple stakeholders. In response to the interest game of the participating entities, some scholars have studied the strategic interaction between government regulation agencies and chemical production enterprises from the perspective of game theory [26,27]. Shen et al. [28] used signaling game theory to study the strategic interaction between government regulation agencies and chemical production enterprises, and proposed methods to improve the efficiency of government safety regulation. Based on the Stackelberg game model, Zhang and Sun [29] analyzed the interaction between government regulation agencies and chemical enterprises from the aspect of the operating efficiency of chemical enterprises and the social benefits of government regulation agencies. The above research, however, was conducted based on complete rationality. In light of the operational management theory and game theory, Cheung and Zhuang [30] considered the impact of strategic interaction between government regulation agencies and competing manufacturing enterprises on corporate safety production and found that strict government regulation is needed in a competitive market environment. In the real process of safety production regulation of chemical enterprises, due to information uncertainty, behavior agents have only limited rationality, and they learn and imitate one other in the process of strategic interaction [31,32]. Thus, the traditional game analysis framework is not applicable. It is necessary to make an analysis by means of the evolutionary game theory [33], which was proposed by Smith and Price [34] in 1973 when analyzing the phenomena of the biological evolution process.

The evolutionary game theory focuses on the asymptotic evolution process of game agents with adaptive learning ability $[35,36]$. Individuals with high fitness will be retained given the evolutionary stability strategy in the evolutionary game theory. Binmore et al. [37] considered the random mutation problem in the evolution process, comprehensively explored the mechanisms of individual dynamics, existing population and imitations, and thus obtained the concept of a dynamic imitator in the evolutionary game theory. Sethi et al. [38] considered that the possibility of strategies being imitated is different, with some strategies difficult to observe and imitate. He proposed a generalized replication dynamic equation. Friedman [39] argued that evolutionary game theory overcame the limitations of traditional games based on the complete rational hypothesis and had great application prospects in the economic field. Therefore, it was closer to reality when studying the safety regulation of chemical enterprises [40-42].

$\mathrm{Yu}$ [43] studied the symmetry of the behavior benefits of coal mine workers from the perspective of game theory and established a system dynamics (SD) model. The simulation results showed that the purpose of enhancing the stability of safety behavior can be achieved through regulating the symmetry of income of coal mine safety managers and coal mine workers by dynamic incentives. Shen [44] analyzed the government's regulatory effect based on the evolutionary game model and concluded that the amount of government penalty and the amount of enterprise safety management investment have the most significant impact on the evolutionary effect. Given the safety production behavior and its regulatory characteristics of industrial cluster enterprises, Liu et al. [45] revealed the evolution law of enterprise safety production behavior selection through the evolution model analysis of the interaction process between government regulation agencies and enterprises. Pi [46] developed a perspective of safety performance (SP) for construction projects in China and put forward a conception of the safety information system to strengthen the safety supervision of participants in the construction 
industry. However, none of the above studies considered the influence of third-party regulation service agencies, nor did they consider the issue of power rent-seeking between third-party regulation service agencies and chemical enterprises, which is a prerequisite for better playing the role of a third party in the safety regulation process of chemical enterprises.

In summary, although the above research has contributed a great deal to the influencing factors and evolution process of the chemical industry's safety production regulation, there are still some shortcomings in the existing research. For instance, most existing research is mainly based on complete rationality, which does not pay attention to the limited rationality of the game agents and the impact of third-party regulation services. Nor does it analyze the rent-seeking behavior between chemical enterprises and the third-party regulatory service agencies. Therefore, this paper incorporates third-party regulation service institutions into the evolutionary game model, systematically analyzes the strategic interaction between government regulation agencies, chemical enterprises and third-party regulation service agencies, and solves the evolutionary equilibrium, while carrying out simulation analyses using the system dynamics theory.

\section{Research Methods}

After Von Neumann and Morganstern proposed the game theory [47], Nash put forward the concept of the Nash equilibrium when discussing non-cooperative game theory [48]. Recently, the game theory has gradually become an important theoretical method of multi-agent strategy interaction. There are three basic assumptions of the traditional classical game theory which obviously have some limitations. First, complete rationality-game agents have unlimited information analysis capabilities to maximize their interests. Second, common knowledge-game agents are rational and have common knowledge. Third, complete information - the game structure and game environment are constant. However, it is necessary to consider the learning and limitation of game agents, analyze the process of strategic interaction, and solve the multiple equilibrium problems [49]. To solve these limitations, the evolutionary game theory based on bounded rationality was proposed. Evolutionary game theory holds that the equilibrium state, very similar to the biological evolution theory, is not achieved in only one step. Maynard proposed the evolutionary game theory and evolution stability strategy (ESS) based on the evolution mechanism of biological populations and limited rationality [37]. The evolutionary game theory abandons complete rationality and complete information hypotheses. Due to the complex environment and their limited ability to analyze information, game agents have only incomplete information, so they have only bounded rationality. The replication dynamics is the most commonly used decision mechanism in the evolutionary game theory because the replication dynamics equations are differential equations that have great mathematical analytical attributes and can be used to analyze the frequency change of each strategy and the final evolutionary stability equilibrium. The evolutionary stability equilibrium is one of the most basic equilibrium concepts. When the game system reaches the evolutionary stability equilibrium, the system will be in a locked state and slight mutations will not cause deviations of the equilibrium [50].

However, the evolutionary stability equilibrium is only a static equilibrium. In order to further study the process of system evolution, the system dynamics (SD) method on the basis of internal feedback mechanism is proposed by some scholars [51]. The system dynamics model is built on the internal linkage and variables of the system and the combination of qualitative and quantitative analysis methods, which can be used to analyze multivariable non-linear complex systems. The system dynamics model includes three types of variables: level variables that represent the state of the environment variable at a certain moment, rate variables that show the change rate of the level variables during a certain period, and auxiliary variables that stand for the parameter values. The relationship among variables constitute the system structure and it is possible to observe the evolutionary process of the equilibrium with the help of simulation software such as VENSIM. Thus, in recent years, the system dynamics theory has been widely used in economic and management research [52]. 


\section{Assumptions and Construction of the Evolutionary Game Model}

\subsection{Basic Assumptions}

According to the above analyses, this paper analyzes the government safety regulation of chemical enterprises under the background of third-party regulation, selects the government, chemical enterprise, and third-party regulation service agency as the main agents, and uses evolutionary game theory to study their strategy interaction. Specific assumptions are as follows:

Assumption 1. The government is group 1, the chemical enterprise is group 2, and the third-party regulation service agency is group 3. At the same time, due to the incomplete and asymmetric information, individuals in each group have only limited rationality.

Assumption 2. In order to facilitate analysis and calculation, this paper purifies the selections of each game agent, assuming that each game agent has only two pure strategy choices regardless of the hybrid strategy. The strategy selection space of the government is (strict safety regulation, loose safety regulation), in which the probability of the government selecting strict safety regulation strategy is $x$ and the probability of choosing loose safety regulation strategy is $1-x$. The strategic selection space for chemical enterprises is (strengthening safety management, maintaining safety management), in which the probability of chemical enterprises choosing to strengthen safety management strategy is y and the probability of choosing not to strengthen safety management strategy is $1-y$. The strategy selection space of the third-party regulation service agency is (rejecting rent-seeking, accepting rent-seeking), in which the probability that the third-party regulator chooses to refuse rent-seeking strategy is $z$ and the probability of selecting the rent-seeking strategy is $1-z$.

Assumption 3. Since government regulation and inspection are costly, it is necessary to invest a certain amount of manpower, material resources, and financial resources; the stricter the regulation, the higher the corresponding regulation cost. Therefore, when the government adopts a strict regulation strategy, its regulation cost is $C_{g s}$. When adopting a loose regulation strategy, its regulation cost is $C_{g l}$. If there is no safety accident in the production process of the chemical enterprise, the social benefit that the government can obtain is $R$. Conversely, when the government loosely supervises, in the event of a safety accident, the social and economic loss caused to the government is $-R$.

Assumption 4. The safety management of chemical enterprises is also costly. When chemical enterprises strengthen safety management, their corresponding safety management costs are relatively high, set to $C_{c s}$. When chemical enterprises do not strengthen safety management, their corresponding safety management costs are relatively low, set to $C_{c l}$. When chemical enterprises strengthen safety management or the third-party regulation service agencies refuse to seek rent and earnestly perform their regulatory obligations, the chemical enterprises can effectively avoid the occurrence of safety accidents, and their corresponding safety management payoff is $P$. When chemical enterprises strengthen safety management, they do not need to seek rent. Only when they do not strengthen safety management will rent-seeking be necessary, and the corresponding rent-seeking cost is $C_{r}$.

Assumption 5. The service cost of the third-party regulation service agency is $C_{t}$ and the compensation fee paid by the government when purchasing the technical service of the third-party regulation service agency is B. When the third-party regulation service agency conducts rent-seeking activities, its rent-seeking payoff is $S$.

Assumption 6. When the government adopts a strict regulation strategy, it can certainly find the willingness and intention of rent-seeking by chemical enterprises or third-party regulation services, and the government will impose penalties on the two types of agents. The amount of punishment for chemical enterprises is $F_{c}$, and the amount of punishment for third-party regulation service agencies is $F_{t}$. When the government adopts a loose regulation strategy it cannot effectively find out whether rent-seeking activities exist or not; then there will be no punishment.

Assumption 7. In order to fit the reality, all variables are positive for the sake of reality. 


\subsection{Model Construction}

Based on the above model assumptions, this paper constructs a three-party payoff matrix of government, chemical enterprises, and third-party regulation service agencies. The first function represents the government's payoff, the second represents the payoff of the chemical enterprise, and the third represents the payoff of a third-party regulation service. The specific form of the payoff matrix of each party is shown in Table 2.

Table 2. Payoff matrix.

\begin{tabular}{|c|c|c|}
\hline \multicolumn{3}{|c|}{ Government Selects Strict Safety Regulation Strategy (x) } \\
\hline & $\begin{array}{l}\text { The third-party regulation service } \\
\text { agency rejects rent-seeking }(z)\end{array}$ & $\begin{array}{l}\text { The third-party regulation service } \\
\text { agency accepts rent-seeking }(1-z)\end{array}$ \\
\hline $\begin{array}{l}\text { Chemical enterprises strengthen } \\
\text { safety management }(y)\end{array}$ & $\begin{array}{c}R-C_{g s}-B \\
P-C_{C S} \\
B-C_{t}\end{array}$ & $\begin{array}{c}R-C_{g s}-B+F_{t} \\
P-C_{c s} \\
B-C_{t}-F_{t}\end{array}$ \\
\hline $\begin{array}{l}\text { Chemical enterprises do not } \\
\text { strengthen safety management } \\
\qquad(1-y)\end{array}$ & $\begin{array}{c}-C_{g s}-B+F_{c} \\
-C_{c l}-F_{c} \\
B-C_{t}\end{array}$ & $\begin{array}{c}-R-C_{g s}-B+F_{t}+F_{c} \\
P-C_{c l}-C_{r}-F_{c} \\
B+S-C_{t}-F_{t}\end{array}$ \\
\hline \multicolumn{3}{|c|}{ Government Selects Loose Safety Regulation Strategy $(1-x)$} \\
\hline & $\begin{array}{l}\text { The third-party regulation service } \\
\text { agency rejects rent-seeking }(z)\end{array}$ & $\begin{array}{l}\text { The third-party regulation service } \\
\text { agency accepts rent-seeking }(1-z)\end{array}$ \\
\hline $\begin{array}{l}\text { Chemical enterprises strengthen } \\
\text { safety management }(y)\end{array}$ & $\begin{array}{c}R-C_{g l}-B \\
P-C_{C S} \\
B-C_{t}\end{array}$ & $\begin{array}{c}R-C_{g l}-B \\
P-C_{c s} \\
B-C_{t}\end{array}$ \\
\hline $\begin{array}{l}\text { Chemical enterprises do not } \\
\text { strengthen safety management } \\
\qquad(1-y)\end{array}$ & $\begin{array}{l}-C_{g l}-B \\
-C_{c l} \\
B-C_{t}\end{array}$ & $\begin{array}{c}-R-C_{g l}-B \\
P-C_{c l}-C_{r} \\
B+S-C_{t}\end{array}$ \\
\hline
\end{tabular}

\subsection{Model Analysis}

\subsubsection{The Replicator Dynamics Equation and the Evolutionary Stability Strategies of Governments}

According to the three-party evolutionary game matrix and basic assumptions constructed above, the probability of the government regulation agencies choosing a strict regulation strategy is $x$, and the probability of government regulation agencies choosing a loose regulation strategy is $1-x$. The expected payoffs of these two kinds of government regulation agencies are symbolized as $U_{x}$ and $U_{1-x}$, respectively, and the overall expected payoff is denoted by $\bar{U}_{x}$

$$
\begin{gathered}
U_{x}=y z\left(R-C_{g s}-B\right)+y(1-z)\left(R-C_{g s}-B+F_{t}\right)+(1-y) z\left(-C_{g l}-B+F_{c}\right) \\
+(1-y)(1-z)\left(-R-C_{g s}-B+F_{t}+F_{c}\right) \\
=2 y R-R-C_{g s}-B+F_{t}+F_{c}-y F_{c}+z R-z F_{t}-y z R \\
U_{1-x}=y z\left(R-C_{g l}-B\right)+y(1-z)\left(R-C_{g l}-B\right)+(1-y) z\left(-C_{g l}-B\right) \\
+(1-y)(1-z)\left(-R-C_{g l}-B\right) \\
=2 y R-R-C_{g l}-B+z R-y z R \\
\bar{U}_{x}=x U_{x}+(1-x) U_{1-x}
\end{gathered}
$$

Furthermore, the dynamic replication equation $F(x)$ of the government regulation agencies can be obtained as follows:

$$
F(x)=\frac{d x}{d t}=x(1-x)\left(U_{x}-U_{1-x}\right)=x(1-x)\left(C_{g l}-C_{g s}+F_{t}+F_{c}-y F_{c}-z F_{t}\right)
$$


The influence of $x$ on the evolutionary stable equilibrium strategy of the government regulation agencies is calculated as:

$$
\frac{d F(x)}{d x}=(1-2 x)\left(C_{g l}-C_{g s}+F_{t}+F_{c}-y F_{c}-z F_{t}\right)
$$

Let $\frac{d F(x)}{d x}=0$, further analysis can be concluded as follows:

Conclusion 1. The probability of $x$ increases while the probability of $y$ increases.

Proof. Set $C_{g l}-C_{g s}+F_{t}+F_{c}-y F_{c}-z F_{t}=0$. The probability threshold for chemical enterprises to strengthen the safety management strategy is:

$$
\lambda_{y}=\frac{C_{g l}-C_{g s}+F_{t}+F_{c}-z F_{t}}{F_{c}}
$$

When $y>\lambda_{y},\left.\frac{d F(x)}{d x}\right|_{x=0}<0$, which indicates that the evolution stable strategy of the government regulation agencies is $x^{*}=0$. That is, government regulation agencies tend to select a strict regulation strategy when the probability of $y$ is higher than $\lambda_{y}$.

When $y<\lambda_{y},\left.\frac{d F(x)}{d x}\right|_{x=1}<0$, which indicates that the evolution stable strategy of the government regulation agencies is $x^{*}=1$. That is, government regulation agencies tend to select a strict regulation strategy when the probability of $y$ is lower than $\lambda_{y}$.

Conclusion 2. The probability of $x$ increases while the probability of $z$ increases.

Proof. Similarly, the probability threshold for third-party regulation service agencies to reject the rent-seeking strategy is:

$$
\lambda_{z}=\frac{C_{g l}-C_{g s}+F_{t}+F_{c}-y F_{c}}{F_{t}}
$$

When $z>\lambda_{z},\left.\frac{d F(x)}{d x}\right|_{x=0}<0$, which indicates that the evolution stable strategy of the government regulation agencies is $x^{*}=0$. That is, government regulation agencies tend to select a strict regulation strategy when the probability of $z$ is higher than $\lambda_{z}$.

When $z<\lambda_{z},\left.\frac{d F(x)}{d x}\right|_{x=1}<0$, which indicates that the evolution stable strategy of the government regulation agencies is $x^{*}=1$. That is, government regulation agencies tend to select a loose regulation strategy when the probability of $z$ is lower than $\lambda_{z}$.

Conclusion 3. When the difference between strict safety regulation cost and loose safety regulation cost is small, and the penalties for third-party regulatory service agencies to seek rent and for chemical enterprises not to strengthen safety management are severe, then the probability that the government will choose a strict regulation strategy will be higher.

Proof. Because $\lambda_{y}=\frac{C_{g l}-C_{g s}+F_{t}+F_{c}-z F_{t}}{F_{c}}$, when $z=1, \underline{y}=\frac{C_{g l}-C_{g s}+F_{c}}{F_{c}}$; when $z=0, \bar{y}=\frac{C_{g l}-C_{g s}+F_{t}+F_{c}}{F_{c}}$. Further, the impact of chemical enterprises' strategy selection on governments' strategy selection is shown in Figure 3.

The volume of $V_{2}$ in Figure 3 represents the proportion of government regulation agencies that choose strict regulation strategy,

$$
V_{2}=\frac{2 C_{g l}-2 C_{g s}+F_{t}+2 F_{c}}{2 F_{c}}
$$


Conclusions through further analysis are as below:

$$
\frac{\mathrm{d} V_{2}}{\mathrm{~d}\left(C_{g s}-C_{g l}\right)}=-\frac{1}{F_{c}}<0
$$

which means the smaller the difference between the strict regulation cost and the loose regulation cost, the higher the probability that the government agencies select the regulation strategy.

$$
\frac{d V_{2}}{d F_{t}}=\frac{1}{2 F_{c}}>0
$$

which means the higher the penalty for the third-party regulation service agencies' rent-seeking behavior, the higher the probability that the government selects the regulation strategy.

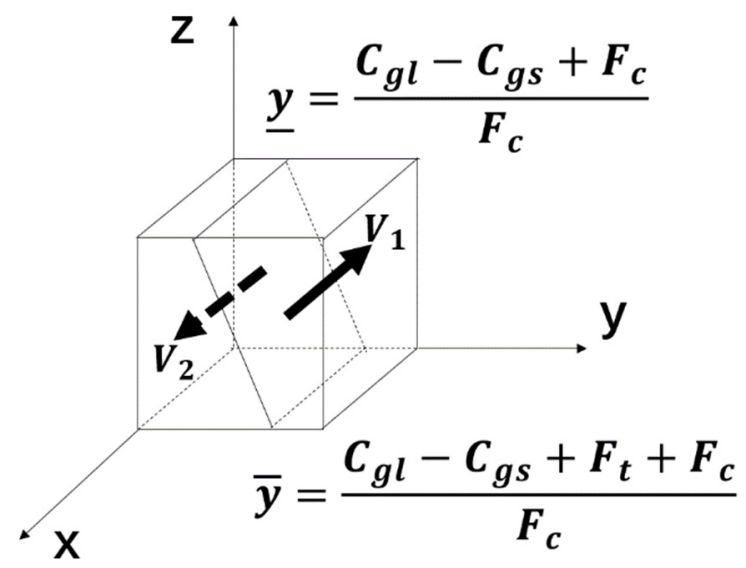

Figure 3. Influence of chemical enterprise strategy selection on the evolutionary equilibrium stable strategy of government regulation agencies.

Similarly, the impact of the third-party regulation service agencies' selections on the government's strategy selection is shown in Figure 4.

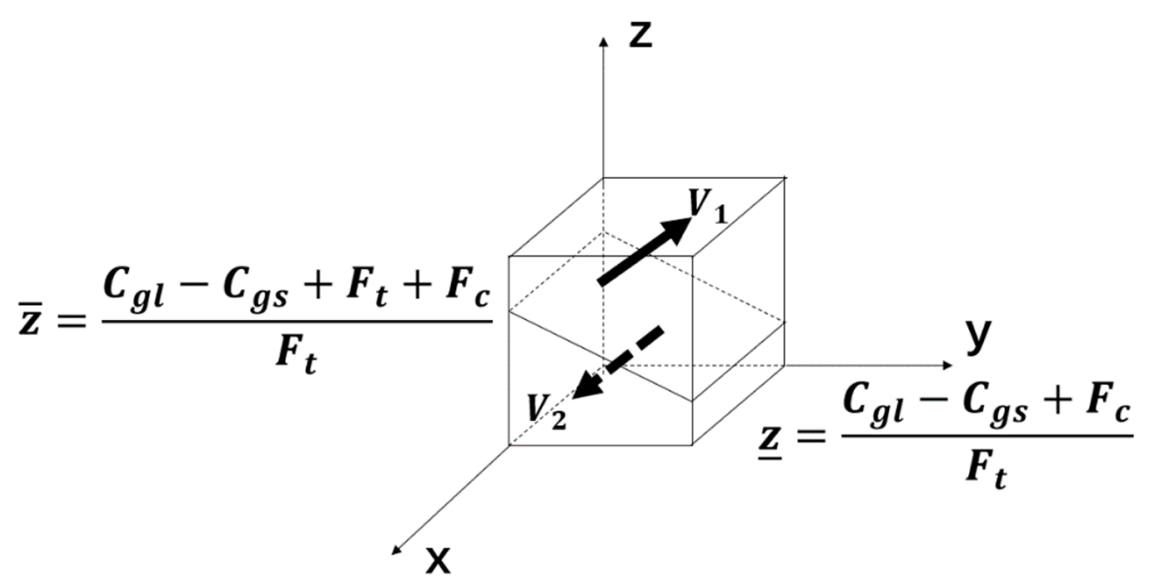

Figure 4. Influence of the third-party regulation service agencies strategy selection on the evolution stable strategy of government regulation agencies.

The volume of $V_{2}=\frac{2 C_{g l}-2 C_{g s}+2 F_{t}+F_{c}}{2 F_{t}}$ in Figure 4 represents the proportion of government regulation agencies that a select strict regulation strategy. Conclusions through further analysis are as follows:

$$
\frac{\mathrm{d} V_{2}}{\mathrm{~d} F_{c}}=\frac{1}{2 F_{t}}>0
$$


which means the higher the punishment for chemical enterprises not to strengthen safety management, the higher the probability of the governments choosing a strict regulation strategy.

4.3.2. The Replicator Dynamics Equation and Evolutionary Stability Strategies of Chemical Enterprises

According to the hypothesis, the probability of chemical enterprises that choose to strengthen safety management strategy is $y$, and the probability of chemical enterprises that choose a loose regulation strategy is $1-y$. The expected payoffs of these two kinds of chemical enterprises are symbolized as $U_{y}$ and $U_{1-y}$, respectively, and the overall expected payoff is denoted by $\bar{U}_{y}$.

$$
\begin{gathered}
U_{y}=x z\left(P-C_{c s}\right)+x(1-z)\left(P-C_{c s}\right)+(1-x) z\left(P-C_{c s}\right) \\
+(1-x)(1-z)\left(P-C_{c s}\right) \\
=P-C_{c s} \\
U_{1-y}=x z\left(-C_{c l}-F_{c}\right)+x(1-z)\left(P-C_{c l}-C_{r}-F_{c}\right)+(1-x) z\left(-C_{c l}\right) \\
+(1-x)(1-z)\left(P-C_{c l}-C_{r}\right) \\
=P-C_{c l}-C_{r}-x F_{c}+z C_{r}-z P \\
\bar{U}_{y}=y U_{y}+(1-y) U_{1-y}
\end{gathered}
$$

Further, the dynamic replication equation $F(y)$ of the chemical enterprises can be obtained as follows:

$$
F(y)=\frac{d y}{d t}=y(1-y)\left(U_{y}-U_{1-y}\right)=y(1-y)\left(-C_{c s}+C_{c l}+C_{r}+x F_{c}-z C_{r}+z P\right)
$$

The influence of $y$ on the evolutionary stable equilibrium strategy of all the chemical enterprises is calculated as:

$$
\frac{d F(y)}{d y}=(1-2 y)\left(-C_{c s}+C_{c l}+C_{r}+x F_{c}-z C_{r}+z P\right)
$$

Let $\frac{d F(y)}{d y}=0$, further analysis can be concluded as follows:

Conclusion 4. The probability of $y$ increases while the probability of $x$ increases.

Proof. Let $-C_{c s}+C_{c l}+C_{r}+x F_{c}-z C_{r}+z P=0$. The probability threshold for the governments to select a strict safety regulation strategy is:

$$
\lambda_{x}=\frac{C_{c S}-C_{c l}-C_{r}+z C_{r}-z P}{F_{c}}
$$

When $x>\lambda_{x},\left.\frac{d F(y)}{d y}\right|_{y=1}<0$, which indicates that the evolution stable strategy of the chemical enterprises is $y^{*}=1$. That is, chemical enterprises tend to strengthen safety management when the probability of $x$ is higher than $\lambda_{x}$.

When $x<\lambda_{x},\left.\frac{d F(y)}{d y}\right|_{y=0}<0$, the evolution stable strategy of the chemical enterprises is $y^{*}=0$. That is, chemical enterprises tend to strengthen security management when the probability of $x$ is lower than $\lambda_{x}$.

Conclusion 5. The probability of $y$ increases while the probability of $z$ increases.

Proof. Similarly, the probability threshold for the third-party regulation service agencies choosing to reject the rent-seeking strategy is:

$$
\lambda_{z}=\frac{C_{c s}-C_{c l}-C_{r}-x F_{c}}{P-C_{r}}
$$


When $z>\lambda_{z},\left.\frac{d F(y)}{d y}\right|_{y=1}<0$, which indicates that the evolution stable strategy of the chemical enterprises is $y^{*}=1$. That is, chemical enterprises tend to strengthen safety management when the probability of $z$ is higher than $\lambda_{z}$.

When $z<\lambda_{z},\left.\frac{d F(y)}{d y}\right|_{y=0}<0$, the evolution stable strategy of the chemical enterprises is $y^{*}=0$. That is, chemical enterprises tend to strengthen security management when the probability of $x$ is lower than $\lambda_{x}$.

Conclusion 6. When the difference between the cost of strengthening safety management and the cost of maintaining safety management is smaller, the rent-seeking cost of chemical enterprises will be higher, the economic benefit obtained by chemical enterprises in strengthening safety management will be higher, and the penalty for chemical enterprises will be heavier, and the possibility of the government regulation agencies choosing to strengthen safety management will be higher.

Proof. It is obtained by $\lambda_{x}=\frac{C_{c s}-C_{c l}-C_{r}+z C_{r}-z P}{F_{c}}$, when $z=1, \underline{x}=\frac{C_{c s}-C_{c l}-P}{F_{c}}$, when $z=0, \bar{x}=\frac{C_{c s}-C_{c l}-C_{r}}{F_{c}}$.

The impact of the government's strategy selection on chemical enterprises' strategic selection is shown in Figure 5.

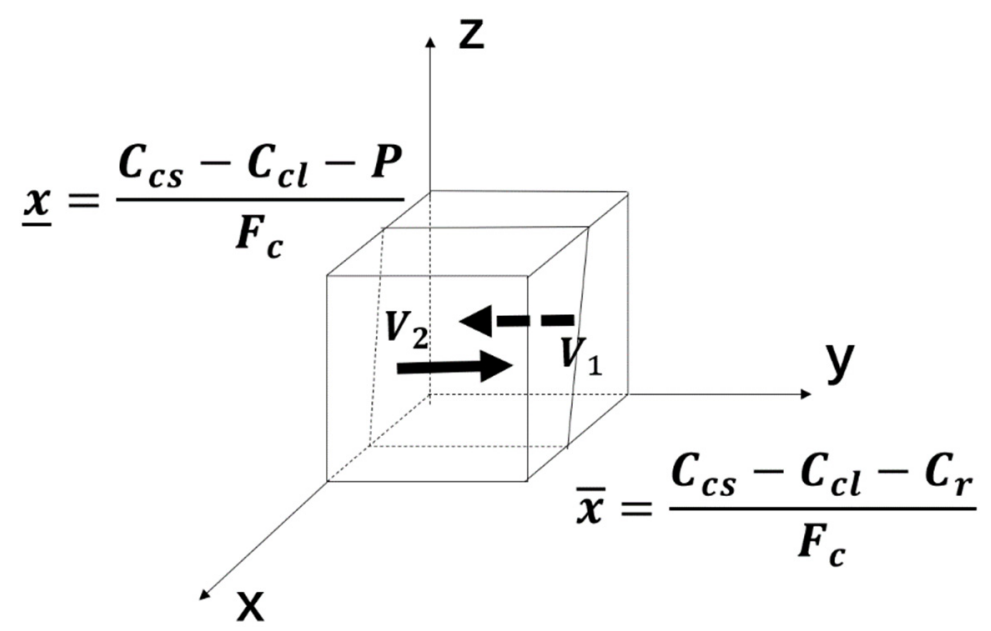

Figure 5. Influence of government strategy selection on the evolutionary equilibrium stable strategy of fossil-energy chemical enterprises.

The volume of $V_{2}$ in Figure 5 represents the proportion of chemical enterprises that choose to strengthen the safety management strategy,

$$
V_{2}=\frac{2 F_{c}-2 C_{c s}+2 C_{c l}+C_{r}+P}{2 F_{c}}
$$

Conclusions through further analysis are as below:

$$
\frac{\mathrm{d} V_{2}}{\mathrm{~d}\left(C_{c s}-C_{c l}\right)}=-\frac{1}{F_{c}}<0
$$

which means the smaller the difference between the cost of strengthening safety management and the cost of maintaining safety management, the higher the probability that the chemical enterprises select the regulation strategy.

$$
\frac{\mathrm{d} V_{2}}{\mathrm{~d} C_{r}}=\frac{1}{2 F_{c}}>0
$$


which means the higher the rent-seeking cost of chemical enterprises, the higher the probability that the chemical enterprises select the regulation strategy.

$$
\frac{\mathrm{d} V_{2}}{\mathrm{~d} P}=\frac{1}{2 F_{c}}>0
$$

which means the higher the economic benefit obtained by chemical enterprises in strengthening safety management, the higher the probability that the chemical enterprises select the regulation strategy.

Similarly, $\lambda_{z}=\frac{C_{c s}-C_{c l}-C_{r}-x F_{c}}{P-C_{r}}$ can be obtained. When $x=1, \underline{z}=\frac{C_{c s}-C_{c l}-C_{r}-F_{c}}{P-C_{r}}$, when $x=0$, $\bar{z}=\frac{C_{C s}-C_{c l}-C_{r}}{P-C_{r}}$, the impact of the third-party regulation service agencies' strategy selection on chemical enterprise strategy selection is shown in Figure 6.

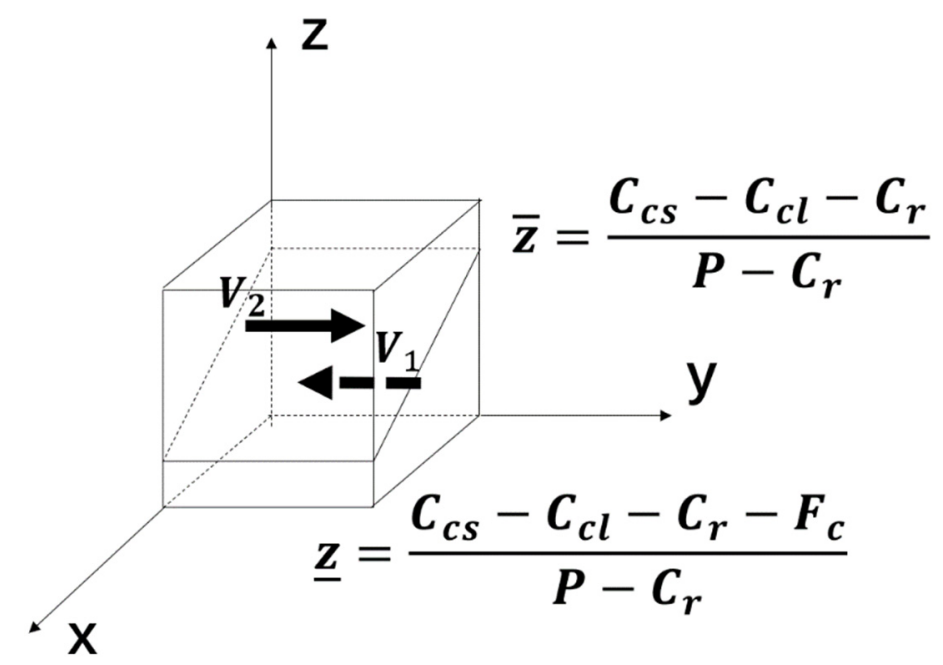

Figure 6. Influence of the third-party regulation service agencies' strategy selection on the evolutionary equilibrium stable strategy of fossil-energy chemical enterprises.

The volume of $V_{2}$ in Figure 6 represents the proportion of chemical enterprises that choose to strengthen their safety management strategy,

$$
V_{2}=\frac{2 P-2 C_{c s}+2 C_{c l}+F_{c}}{2 P-2 C_{r}}
$$

Conclusions through further analysis are as follows:

$$
\frac{\mathrm{d} V_{2}}{\mathrm{~d} F_{c}}=\frac{1}{2 P-2 C_{r}}>0
$$

which means the higher the penalty for chemical enterprises, the higher the probability that the chemical enterprises select the regulation strategy.

4.3.3. The Replicator Dynamics Equation and Evolutionary Stability Strategies of the Third-Party Regulation Service Agencies

The probability of the third-party regulation service agencies choosing to reject the rent-seeking strategy is $z$, and the probability of the third-party regulation service agencies choosing to accept the rent-seeking strategy is $1-z$. The expected payoffs of these two kinds of third-party regulation service agencies are symbolized as $U_{z}$ and $U_{1-z}$, respectively, and the overall expected payoff is denoted by $\bar{U}_{y}$ :

$$
\begin{gathered}
U_{z}=x y\left(B-C_{t}\right)+x(1-y)\left(B-C_{t}\right)+(1-x) y\left(B-C_{t}\right)+(1-x)(1-y)\left(B-C_{t}\right) \\
=B-C_{t}
\end{gathered}
$$




$$
\begin{gathered}
U_{1-z}=x y\left(B-C_{t}-F_{t}\right)+x(1-y)\left(B+S-C_{t}-F_{t}\right)+(1-x) y\left(B-C_{t}\right) \\
+(1-x)(1-y)\left(B+S-C_{t}\right) \\
=-x F_{t}+B+S-y S-C_{t} \\
\bar{U}_{z}=z U_{z}+(1-z) U_{1-z}
\end{gathered}
$$

Further, the dynamic replication equation $F(z)$ of the third-party regulation service agencies can be obtained as follows:

$$
F(z)=\frac{d z}{d t}=z(1-z)\left(U_{z}-U_{1-z}\right)=z(1-z)\left(x F_{t}-S+y S\right)
$$

The influence of $z$ on the evolutionary stable equilibrium strategy of the third-party regulation service agencies is calculated as:

$$
\frac{d F(z)}{d z}=(1-2 z)\left(x F_{t}-S+y S\right)
$$

Let $\frac{d F(z)}{d z}=0$, further analysis can be concluded as follows:

Conclusion 7. The probability of $z$ increases while the probability of $x$ increases.

Proof. Let $x F_{t}-S+y S=0$, the probability threshold for the governments to select a strict safety regulation strategy is:

$$
\lambda_{x}=\frac{S-y S}{F_{t}}
$$

When $x>\lambda_{x},\left.\frac{d F(z)}{d z}\right|_{z=1}<0$, which indicates that the evolution stable strategy of the third-party regulation service agencies is $z^{*}=1$. That is, the third-party regulation service agencies tend to reject the rent-seeking when the probability of $x$ is higher than $\lambda_{x}$.

When $x<\lambda_{x},\left.\frac{d F(z)}{d z}\right|_{z=0}<0$, which indicates that the evolution stable strategy of the third-party regulation service agencies is $z^{*}=0$. That is, the third-party regulation service agencies tend to accept the rent-seeking when the probability of $x$ is lower than $\lambda_{x}$.

Conclusion 8 . The probability of $z$ increases while the probability of $y$ increases.

Proof. Similarly, the probability threshold for chemical enterprises to strengthen their safety management strategy is:

$$
\lambda_{y}=\frac{S-x F_{t}}{S}
$$

When $y>\lambda_{y},\left.\frac{d F(z)}{d z}\right|_{z=1}<0$, which indicates that the evolution stable strategy of the third-party regulation service agencies is $z^{*}=1$. That is, the third-party regulation service agencies tend to reject the rent-seeking when the probability of $y$ is higher than $\lambda_{y}$.

When $y<\lambda_{y},\left.\frac{d F(z)}{d z}\right|_{z=0}<0$, which indicates that the evolution stable strategy of the third-party regulation service agencies is $z^{*}=0$. That is, the third-party regulation service agencies tend to accept the rent-seeking when the probability of $y$ is lower than $\lambda_{y}$.

Conclusion 9. When the possibility of the third-party regulation service agencies accepting rent-seeking is higher, the economic benefits for chemical enterprises to strengthen safety management is lower, and the probability of the third-party regulation service agencies choosing to reject rent-seeking will be higher.

Proof. It can be obtained by $\lambda_{x}=\frac{S-y S}{F_{t}}$, when $y=1, \underline{x}=0$, when $y=0, \bar{x}=\frac{S}{F_{t}}$. The impact of chemical enterprises' selections on the third-party regulation service agencies' strategy selection is shown in Figure 7. 


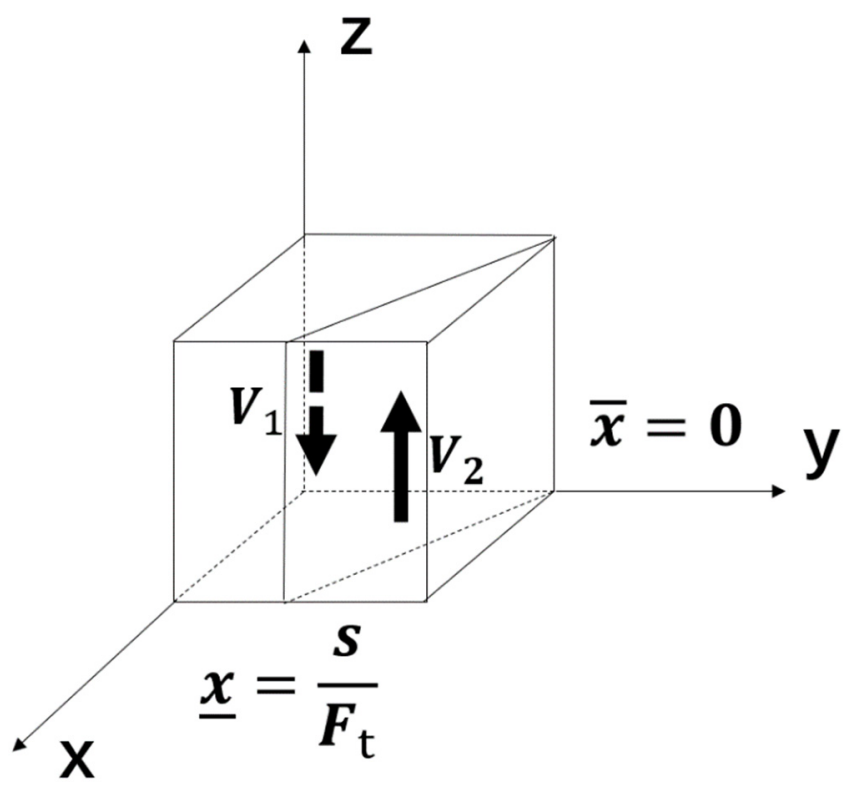

Figure 7. Influence of governments strategy selection on the evolutionary equilibrium stable strategy of the third-party regulation service agencies.

The volume of $V_{2}$ in Figure 7 represents the proportion of the third-party regulation service agencies that choose to reject the rent-seeking strategy,

$$
V_{2}=\frac{2 F_{t}-S}{2 F_{t}}
$$

Conclusions through further analysis are as below:

$$
\frac{d V_{2}}{d F_{t}}=\frac{S}{2 F_{t}^{2}}>0
$$

which means the higher the possibility of the third-party regulation service agencies accepting rent-seeking, the greater the probability that the third-party regulation service agencies choose to reject rent-seeking.

$$
\frac{d V_{2}}{d S}=-\frac{1}{2 F_{t}}<0
$$

which means the lower the economic benefits for chemical enterprises to strengthen safety management, the higher the probability that the third-party regulation service agencies choose to reject rent-seeking.

\section{System Dynamics Simulation Analysis}

Although the above analysis shows the interaction of the strategic selections of all agencies and the influence of major external variables on the evolutionary stable equilibrium, and some conclusions have been obtained, most of the above work is carried out from the perspective of a single group. There is no systematic or comprehensive analysis from the perspective of multiple groups. In the 1950s, Fletcher of the Massachusetts Institute of Technology first adopted the theory of management science and systems science and combined computerized simulation technology with quantitative analysis to propose a system dynamics theory method. It is mainly used to study system problems with high nonlinearity, that are multivariate, have causal feedback and complex time-varying.

Therefore, in order to analyze the strategic interaction between different groups in a more systematic and in-depth manner, this study also uses the system dynamics theory to construct a third-party regulation evolutionary model based on the characteristics of multivariate. The dynamic 
model of the third-party regulation for chemical enterprises safety production, and the simulation of system dynamics with VENSIM PE32 simulation software are employed to analyze the evolution of the strategic interaction.

\subsection{System Dynamics Evolutionary Game Model}

The main variables involved in government regulation of chemical enterprises safety production are assigned in Table 3.

Table 3. Meaning and assignment of model variables.

\begin{tabular}{cccc}
\hline Variable & Sign & Unit & Initial Value \\
\hline Cost of government's strict regulation & $C_{g s}$ & million yuan & 10 \\
\hline Cost of government's loose regulation & $C_{g l}$ & million yuan & 6 \\
\hline Social benefits of chemical enterprises' safety production & $R$ & million yuan & 100 \\
\hline Cost for chemical enterprises to strengthen safety management & $C_{c s}$ & million yuan & 25 \\
\hline Cost for chemical enterprises not to strengthen safety management & $C_{c l}$ & million yuan & 5 \\
\hline Economic benefits for chemical enterprises to strengthen safety management & $P$ & million yuan & 50 \\
\hline Rent-seeking cost of chemical enterprises & $C_{r}$ & million yuan & 10 \\
\hline Service cost of third-party regulation service agencies & $C_{t}$ & million yuan & 15 \\
\hline Payments of third-party regulation service agencies & $B$ & million yuan & 20 \\
\hline Rent-seeking payoff of third-party regulation service agencies & $S$ & million yuan & 5 \\
\hline Government's penalty for chemical enterprises & $F_{c}$ & million yuan & 20 \\
\hline Government's penalty for third-party regulation service agencies & $F_{t}$ & million yuan & 10 \\
\hline
\end{tabular}

According to the above analysis, the replication dynamic equations $F(X, Y, Z)$ is as follows:

$$
F(X, Y, Z)=\left\{\begin{array}{c}
F(x)=x(1-x)\left(C_{g l}-C_{g S}+F_{t}+F_{c}-y F_{c}-z F_{t}\right) \\
F(y)=y(1-y)\left(-C_{c s}+C_{c l}+C_{r}+x F_{c}-z C_{r}+z P\right) \\
F(z)=z(1-z)\left(x F_{t}-S+y S\right)
\end{array}\right.
$$

The system dynamics simulation environment is set as follows: INITIAL TIME $=0$, FINAL TIME $=5$, TIME STEP $=0.0078125$, units for time take a year. By analyzing the relationship between the variables, the system dynamic flow chart is obtained, as shown in Figure 8.

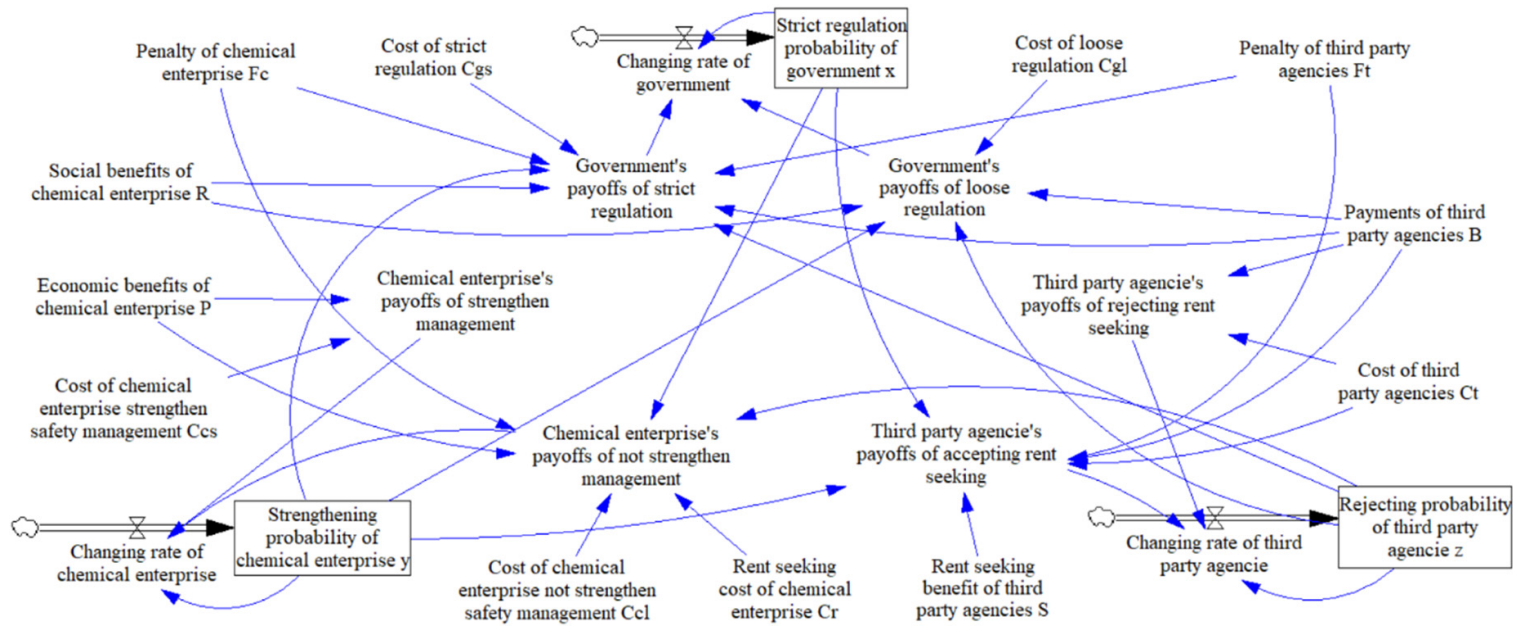

Figure 8. The government regulation of chemical enterprises safety management system dynamics (SD) model. 


\subsection{The Analysis of The Evolutionary Process}

When the initial evolution state is $(0.1,0.1,0.1)$, the evolution of the tripartite strategy is shown in Figure 9. It is not difficult to see that the government dominates the interaction process of the tripartite strategy in order to prevent the occurrence of safety incidents in the production process of chemical enterprises. In the initial stage, a strict regulation strategy is implemented to encourage chemical enterprises to strengthen safety management and guide third-party regulation service agencies to refuse rent-seeking. After the formation of a standardized regulatory order, the government gradually relaxes the regulation strategy in order to reduce the cost of regulation, and eventually achieves an evolutionary stable equilibrium $(0,1,1)$. The efficiency of introducing the third-party regulation service mechanism into the chemical enterprise safety regulation can be proven by reducing the government's safety regulation cost and enhancing chemical enterprises' production safety at the same time.

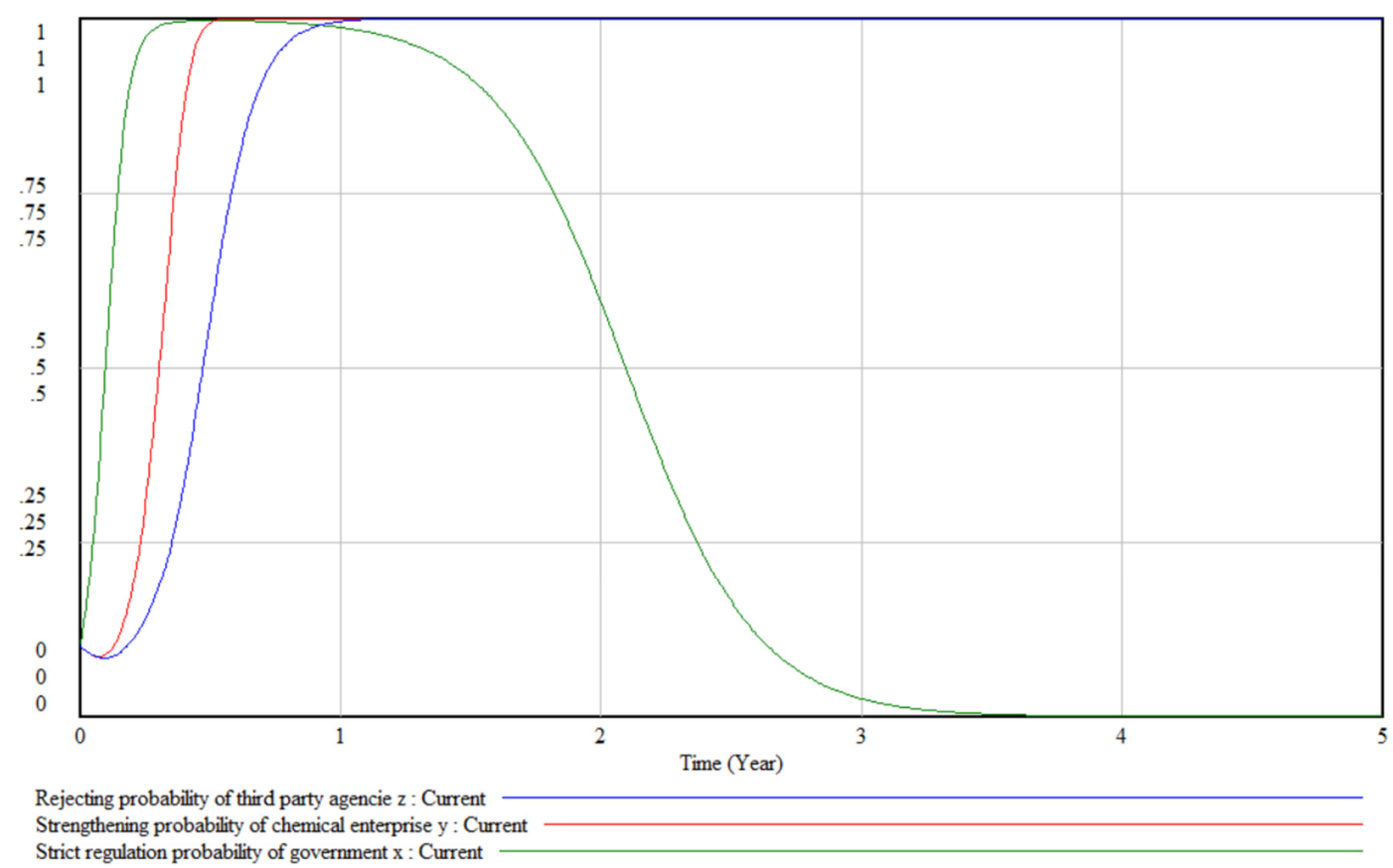

Figure 9. Evolutionary processes of chemical enterprises' safety regulation.

In order to further test the uniqueness of evolutionary stable equilibrium, this paper also carries out the Jacobian test. First, the external parameters are brought into the replication dynamic equations $F(X, Y, Z)=0$. There are eight evolutionary equilibrium states in the evolutionary game model of chemical enterprises which can be obtained by MATLAB, namely: $\mathrm{O}_{1}=(0,0,0), \mathrm{O}_{2}=(1,0,0)$, $\mathrm{O}_{3}=(0,1,0), \mathrm{O}_{4}=(0,0,1), \mathrm{O}_{5}=(1,1,0), \mathrm{O}_{6}=(1,0,1), \mathrm{O}_{7}=(0,1,1), \mathrm{O}_{8}=(1,1,1)$. In order to clarify which equilibrium state is the evolutionary stable equilibrium state, the corresponding Jacques matrix $J$ is obtained as follows:

$$
\begin{aligned}
& J=\left[\begin{array}{lll}
\frac{d F(x)}{d x} & \frac{d F(x)}{d y} & \frac{d F(x)}{d z} \\
\frac{d F(y)}{d x} & \frac{d F(y)}{d y} & \frac{d F(y)}{d z} \\
\frac{d F(z)}{d x} & \frac{d F(z)}{d y} & \frac{d F(z)}{d z}
\end{array}\right]= \\
& {\left[\begin{array}{ccc}
34-20 y-10 z-68+4 x y+20 x z & -20 x+20 x^{2} & -10 x+10 x^{2} \\
20 y-20 y^{2} & 6+20 x+40 z-12 y-40 x y-80 y z & 40 y-40 y^{2} \\
10 z-10 z^{2} & 5 z-5 z^{2} & -5+10 x+5 y+10 z-20 x z-10 y z
\end{array}\right]}
\end{aligned}
$$

We solve the eigenvalues of each partial equilibrium point and judge the attributes accordingly. The eigenvalues and attributes of each equilibrium point are shown in Table 4. 
Table 4. Attribute analysis of evolutionary equilibrium points.

\begin{tabular}{ccccc}
\hline Equilibrium Point & \multicolumn{3}{c}{ Eigenvalues } & Attributes \\
\hline $\mathrm{O}_{1}=(0,0,0)$ & -34 & -5 & 6 & Saddle point \\
$\mathrm{O}_{2}=(1,0,0)$ & -34 & 5 & 26 & Saddle point \\
$\mathrm{O}_{3}=(0,1,0)$ & -54 & 0 & -6 & Saddle point \\
$\mathrm{O}_{4}=(0,0,1)$ & -44 & 5 & 46 & Saddle point \\
$\mathrm{O}_{5}=(1,1,0)$ & -44 & 10 & -26 & Saddle point \\
$\mathrm{O}_{6}=(1,0,1)$ & -24 & -5 & 66 & Saddle point \\
$\mathrm{O}_{7}=(0,1,1)$ & -40 & -10 & -66 & Stable point \\
$\mathrm{O}_{8}=(1,1,1)$ & -64 & 0 & -46 & Saddle point \\
\hline
\end{tabular}

The equilibrium point attribute analysis is consistent with the system dynamics simulation analysis. $\mathrm{O}_{7}=(0,1,1)$ is the evolutionary stable strategy (ESS). Therefore, under the punishment mechanism, the evolutionary game model of chemical industry safety regulations based on third-party participation has only one evolutionary stable equilibrium.

The simulation analysis also found that the strategic selection of the government regulation agencies has a significant impact on the strategic selection of chemical enterprises. As shown in Figures 10 and 11: Current1: $x=0.1, y=0.1, z=0.1$; Current2: $x=0.5, y=0.1, z=0.1$; Current3: $x$ $=0.9, y=0.1, z=0.1$. When the probability of governments selecting a strict regulation strategy is greater, chemical production enterprises tend to choose to strengthen security management strategies in order to avoid government punishment, and the third-party regulation service agencies tend to reject rent-seeking. What is more, with the increasing probability of strict government regulation, fewer iterations are needed for chemical enterprises' strategy selections to reach the evolutionary steady state and the evolution process becomes faster; then the number of iterations required by the third-party regulation service agencies to achieve a stable equilibrium state are reduced accordingly.

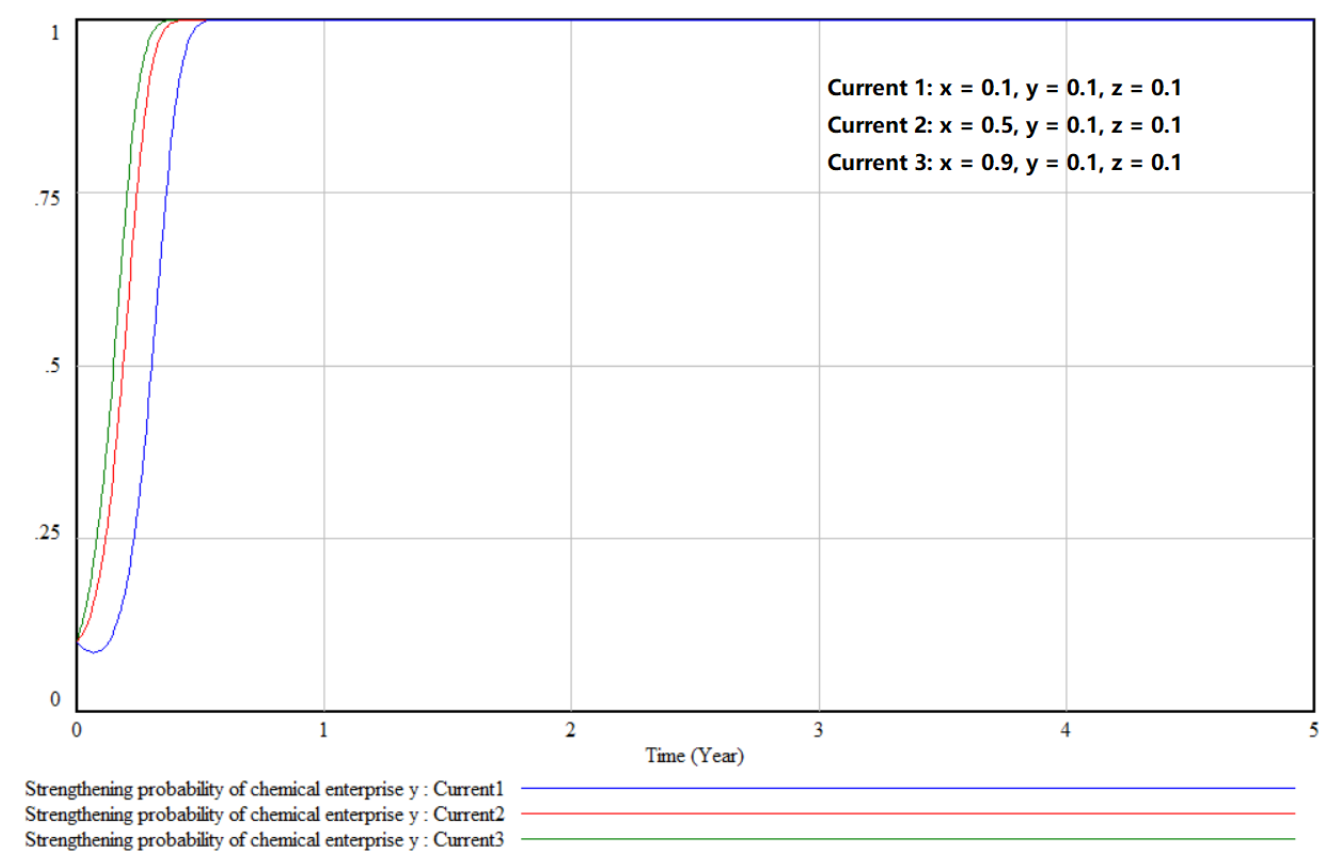

Figure 10. Impact of $\mathrm{x}$ on chemical enterprises' strategy selection.

The strategy selection of third-party regulation service agencies also has a significant impact on government behavior. As shown in Figure 12: Current1: $x=0.1, y=0.1, z=0.1$; Current2: $x=0.1$, $y=0.1, z=0.5$; Current3: $x=0.1, y=0.1, z=0.9$. When the third-party regulation service agencies willing to seek rent account for a relatively high proportion, the government regulation agencies tend to choose a strict regulation strategy to reduce the occurrence of rent-seeking behavior, thereby regulating 
industry behavior and avoiding safety accidents and corresponding losses in the production process of chemical enterprises. When the third-party regulation service agencies that refuse rent-seeking account for a relatively high proportion, the government regulation agencies tend to choose a loose regulation strategy to minimize the regulation cost and rely more on technical talents of third-party regulation service agencies. In addition, when the proportion of third-party regulation services agencies that choose to reject the rent-seeking strategy is higher, fewer iterations are needed to reach the evolutionary stable equilibrium, and shorter time is demanded to achieve regulatory objectives. Therefore, the government should choose high-quality third-party regulation service agencies to reduce the negative impact of rent-seeking behavior.

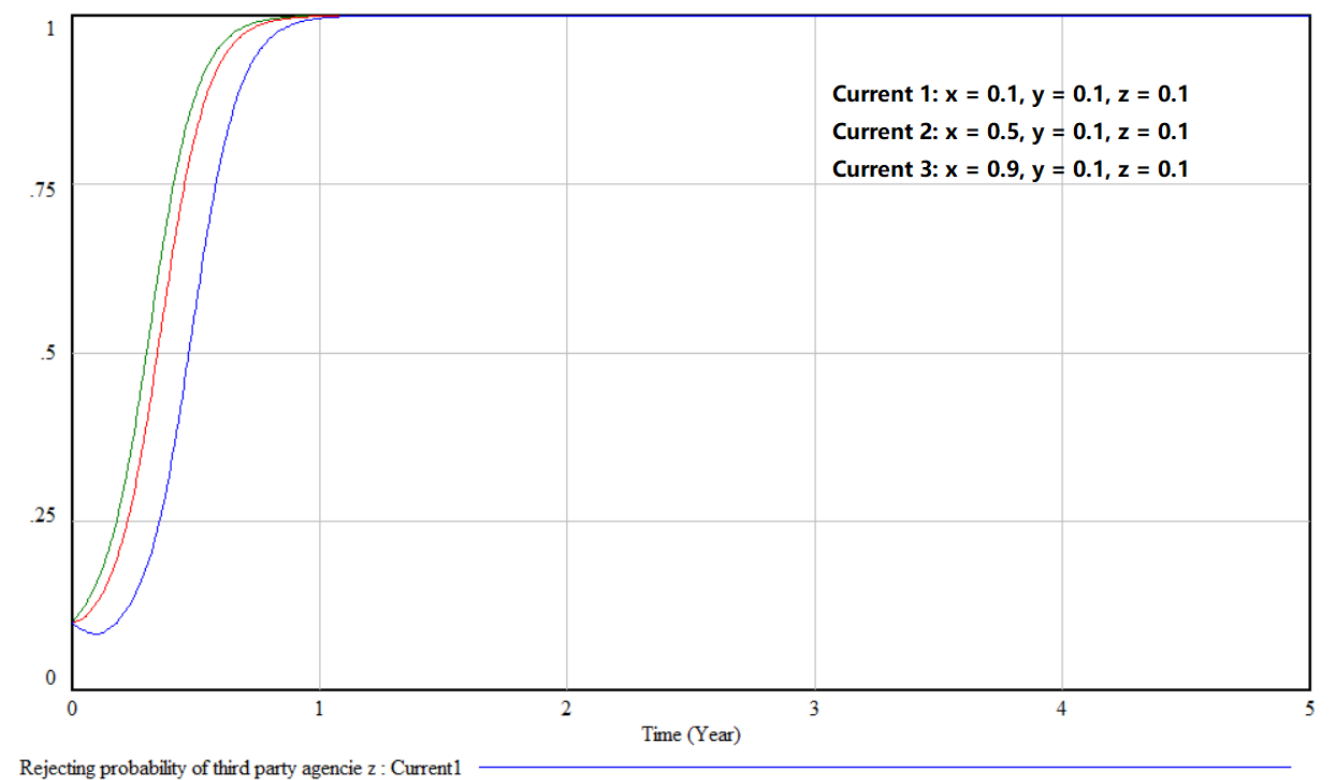

Rejecting probability of third party agencie $\mathrm{z}$ : Current 1

Rejecting probability of third party agencie $\mathrm{z}$ : Current 2
Rejecting probability of third party agencie $\mathrm{z}$ : Current3

Figure 11. Impact of $x$ on third-party regulation service agencies' strategy selection.

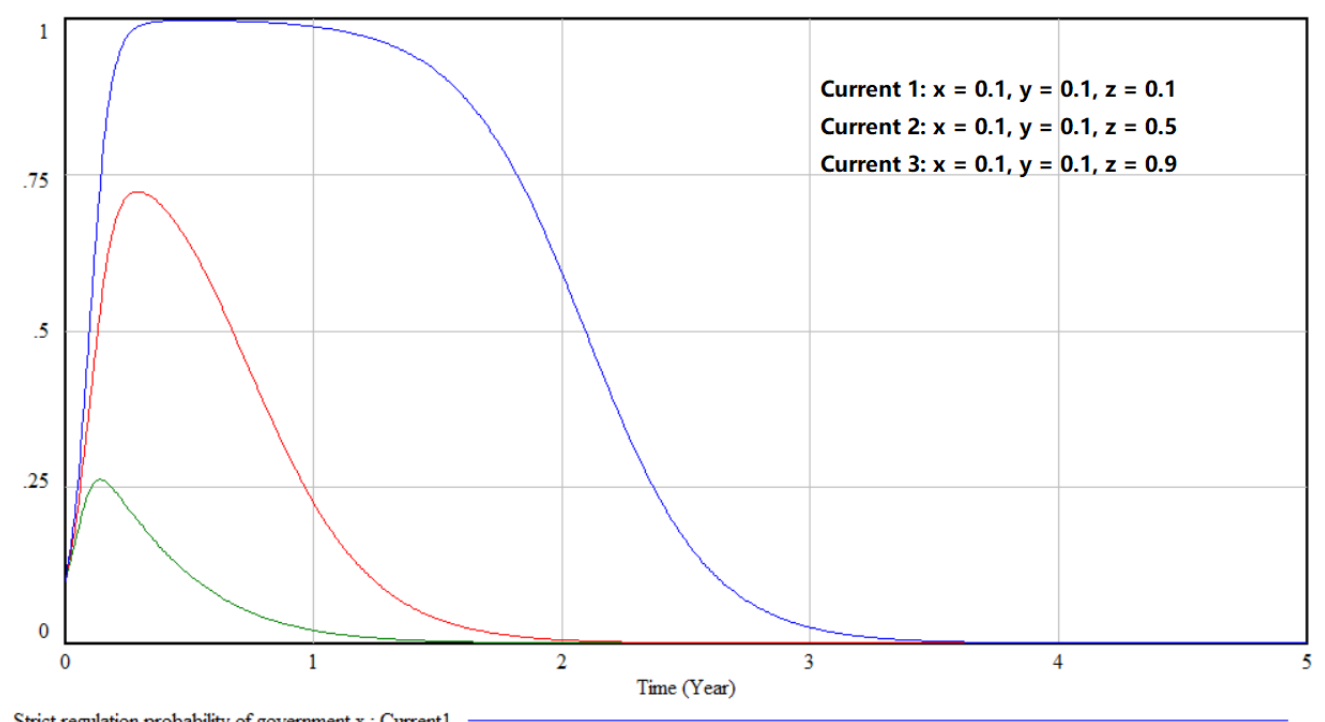

Strict regut

Strict regulation probability of government $x$ : Current 3

Figure 12. Impact of $\mathrm{z}$ on governments' strategy selection. 


\subsection{Analysis of the Influence of Exogenous Variables}

The main measure of government regulation is the punishment mechanism. Therefore, it is necessary to analyze the influence of government penalty on the chemical enterprise that does not strengthen the safety management and the third-party regulation service agencies that are willing to seek rent. Figures 13 and 14 show the impact of the penalty $F_{c}$ on the strategy selection of chemical enterprises and the impact of penalty $\mathrm{F}_{e}$ on the strategy selection of third-party regulation service agencies. As shown in Figures 13 and 14: Current1: $F_{c}=0, F_{e}=0$; Current2: $F_{c}=20, F_{e}=10$; Current3: $F_{c}=40, F_{e}=20$. It is not difficult to see that when the amount of punishment is too light, not only does the chemical industry lack the incentive to strengthen safety management, but also the third-party regulation service agencies are inclined to carry out rent-seeking activities, which cannot effectively prevent safety accidents. With the increase of punishment, fewer iterations are required to reach an evolutionary stable equilibrium, the evolution process gets faster, and the regulation effect of the government will be more effective. Therefore, the government should increase penalties in order to urge chemical enterprises to maintain safety management and prevent third-party regulation service agencies to seek rent.

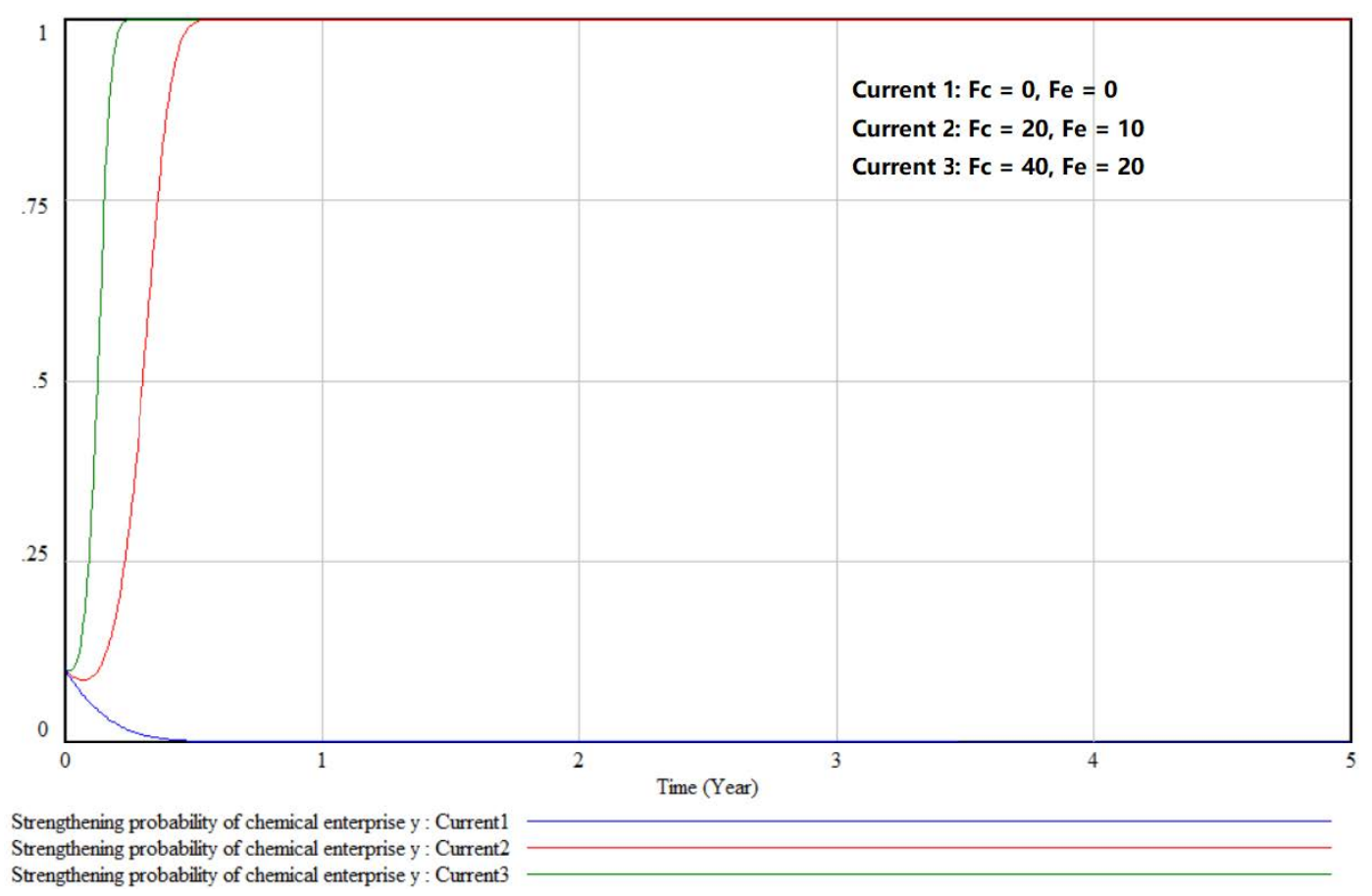

Figure 13. Impact of government penalty on chemical enterprises' strategy selection.

The impact of the rent-seeking $\operatorname{cost} \mathrm{C}_{r}$ and the rent-seeking payoff $\mathrm{S}$ on the strategy selection of the chemical enterprises and third-party regulation service agencies is shown in Figures 15 and 16, respectively. As shown in Figures 15 and 16: Current1: $C_{r}=10, S=5$; Current2: $C_{r}=30, S=15$; Current3: $C_{r}=50, S=25$. The higher the rent-seeking $\operatorname{cost} C_{r}$, the more enthusiastic the chemical enterprises will be to strengthen safety management; the lower the rent-seeking payoff $S$, the more enthusiastic the third-party regulation service agencies will be to refuse rent-seeking. Therefore, a government should improve the market access threshold for third-party regulation service agencies, classify third-party regulation service agencies to promote standardization and formalization, and make use of the media's social regulation role to raise the rent-seeking costs of chemical enterprises and reduce the rent-seeking payoff of third-party regulation service agencies, thus effectively avoiding chemical industry safety accidents. 


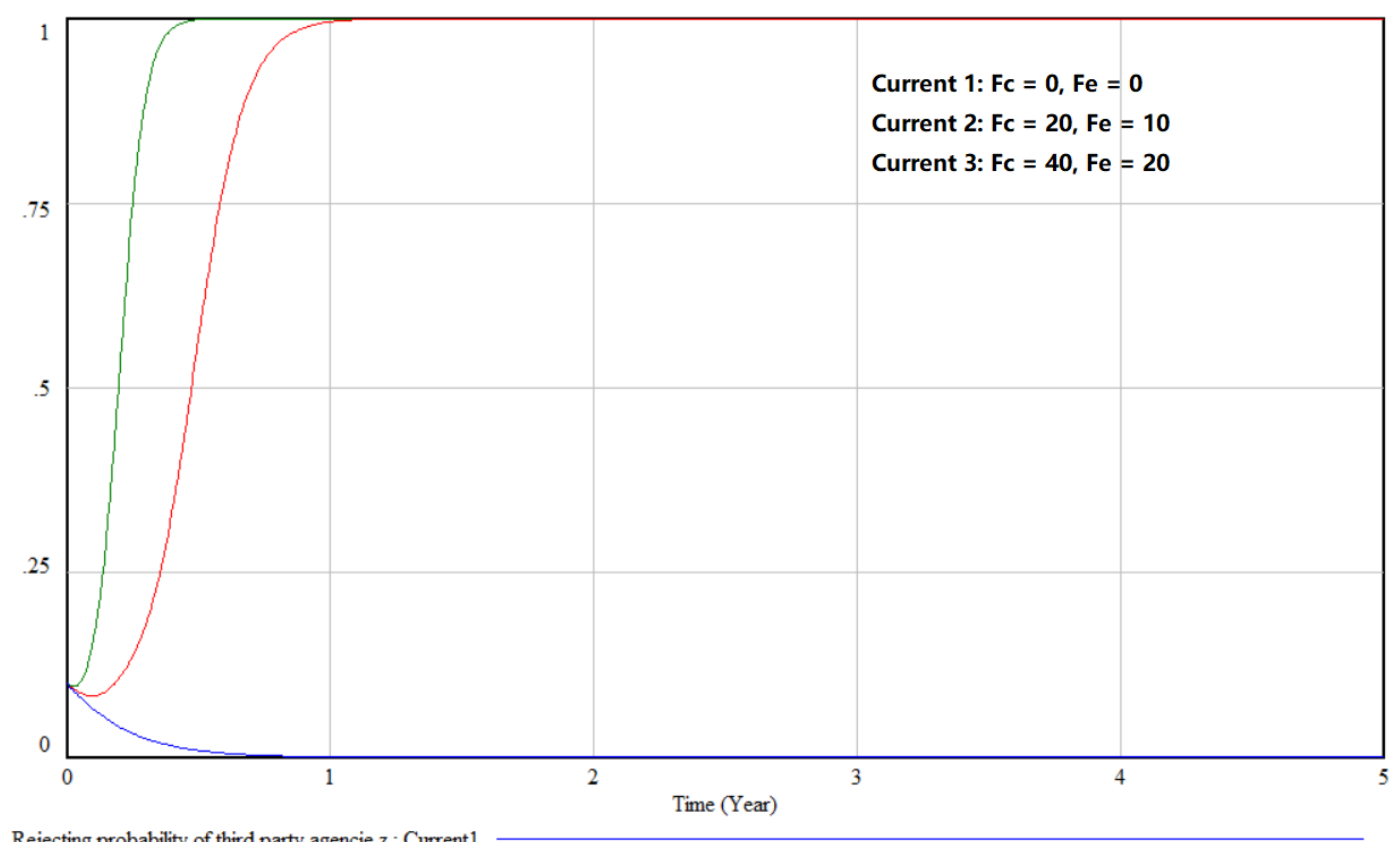

Rejecting probability of third party agencie $\mathrm{z}$ : Current 1

Rejecting probability of third party agencie $\mathrm{z}$ : Current 2

Rejecting probability of third party agencie $z$ : Current 3

Figure 14. Impact of government penalty on third-party regulation service agencies' strategy selection.

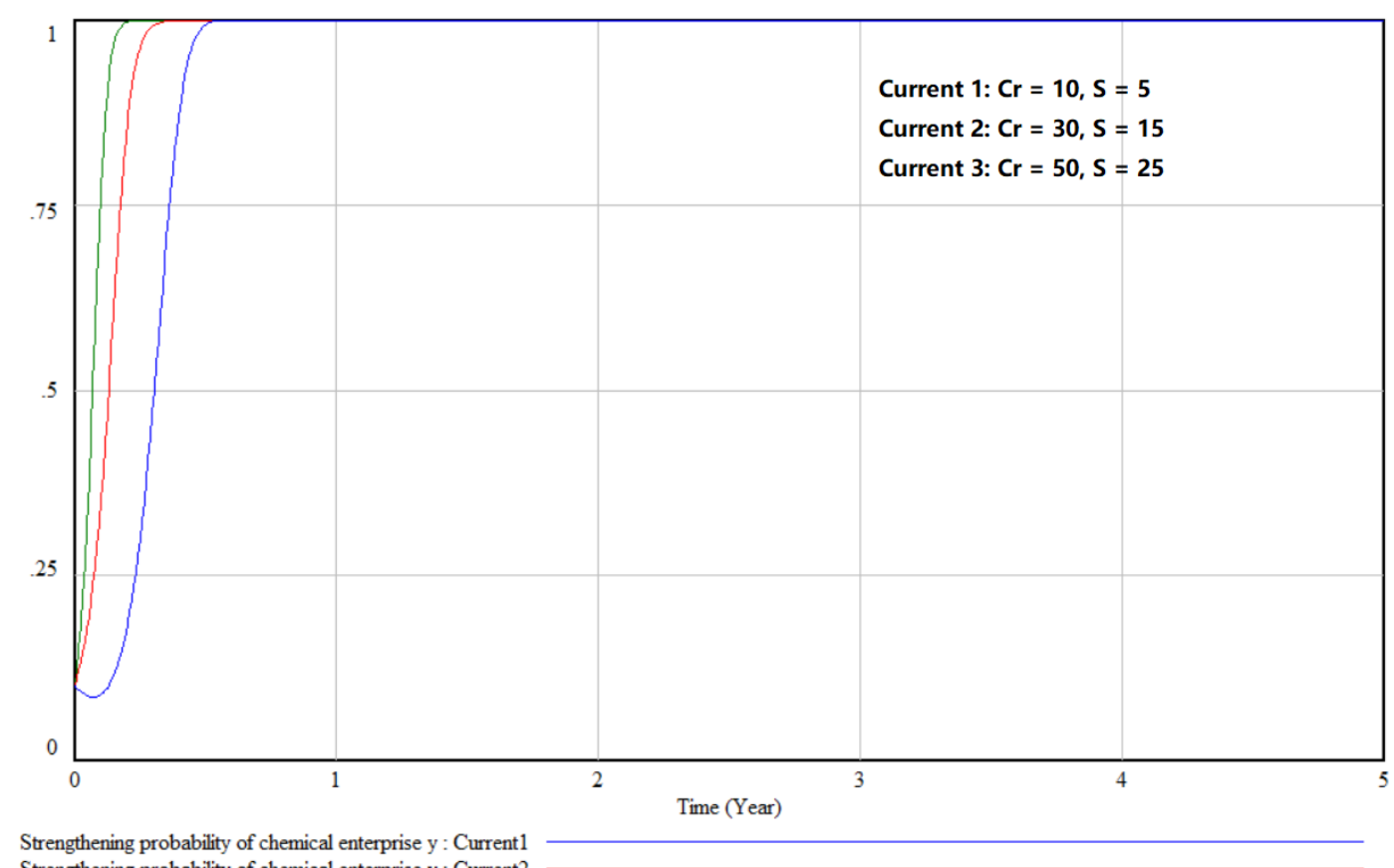

Strengthening probability of chemical enterprise y: Current

Strengthening probability of chemical enterprise $y$ : Current 3

Figure 15. Impact of $C_{r}$ and $S$ on chemical enterprises' strategy selection. 


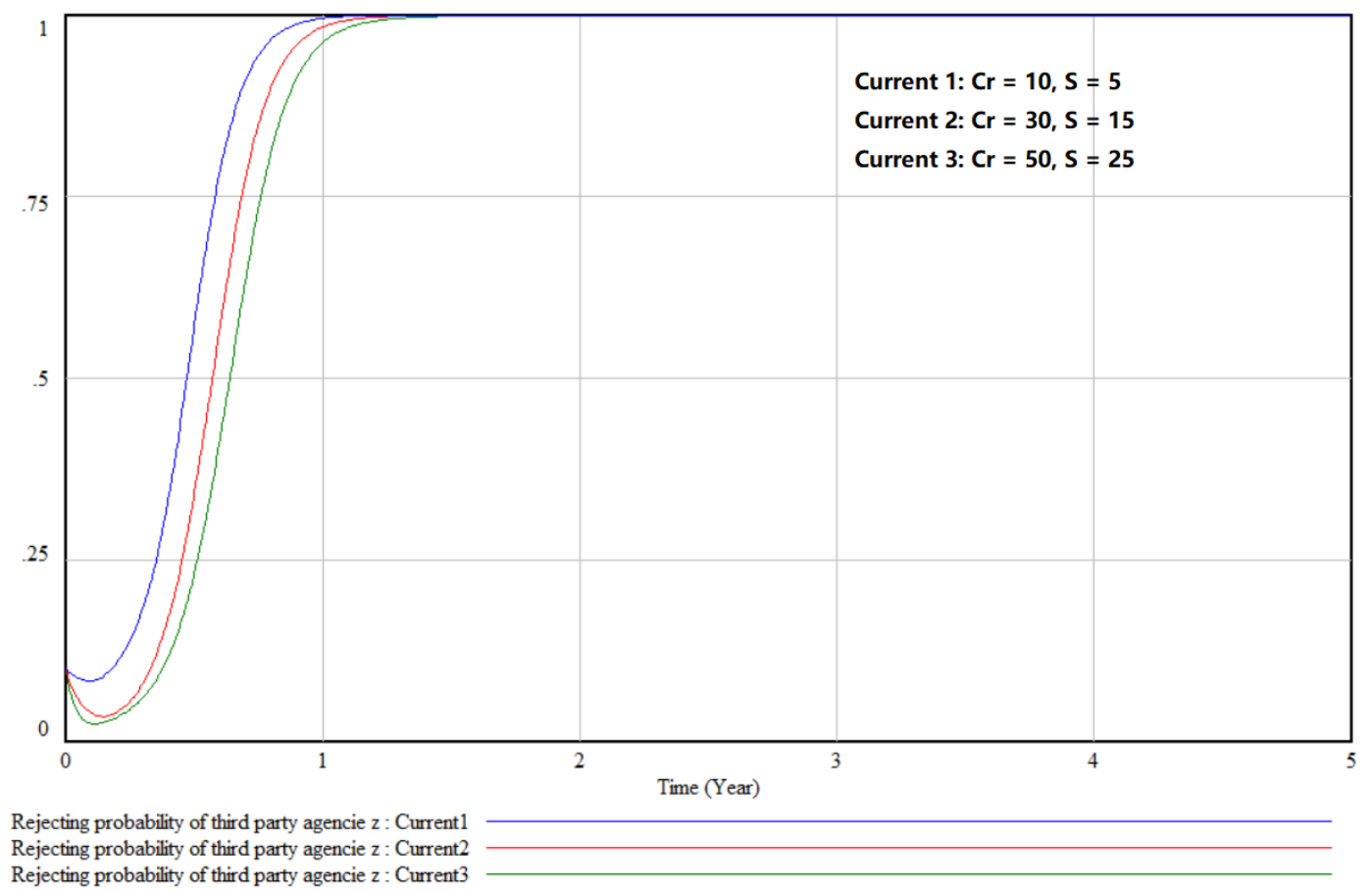

Figure 16. Impact of $C_{r}$ and $S$ on third-party regulation service agencies' strategy selection.

\section{Conclusions}

The chemical industry is one of the pillar industries in China and plays an important role in the development of China's national economy. Though it has developed rapidly in recent years, the frequent occurrence of chemical production safety accidents has seriously affected social life and public safety. In view of the safety production regulation of chemical enterprises, this paper introduces a third-party regulation service mechanism, builds an evolutionary game model based on the strategy interaction of government regulation departments, chemical production enterprises and third-party regulation service institutions, and analyzes the mutual influence and evolutionary stable equilibrium. At the same time, according to the payoff matrix, the influence of external variables on the regulation process is studied by means of system dynamics simulation analysis. The research conclusions are as follows:

(1) The government regulation authorities occupy a dominant position in the process of tripartite strategic interaction and play a guiding role in the strategic interaction of chemical enterprises and third-party regulation service agencies, which can effectively enhance the enthusiasm of chemical enterprises to strengthen safety management and avoid rent-seeking behaviors of third-party regulation service agencies. Results of simulation analyses show that the higher the probability for the government regulation agencies to adopt a strict regulation strategy, the faster the evolutionary stable equilibrium will be achieved, and the more efficient the safety regulation will be. Therefore, government regulation authorities should pay attention to the safety regulation of chemical production, and effectively guide chemical enterprises and third-party regulation service agencies to inhibit the occurrence of chemical accidents.

(2) Whether chemical enterprises attach importance to safety management is mainly affected by the punishment of government regulatory authorities and the cost of rent-seeking. Greater punishment and higher rent-seeking costs can make chemical enterprises more willing to strengthen safety management. The government should comprehensively adopt legal and administrative means to punish enterprises that exhibit illegal behavior and ignore safety production management. At the same time, the government should further improve the safety regulation mechanism, strictly 
enforce the safety regulation norm, increase the rent-seeking cost of chemical enterprises that violate regulations, and finally form a safe production environment for the chemical industry.

(3) The introduction of a third-party regulation service mechanism is of great significance for changing the current dilemma, curbing the frequent occurrence of safety incidents in China, solving the problem of limited professional talents in the process of chemical production safety regulation, and ensuring social stability and the safety of peoples' lives and property. The third-party regulation service mechanism can help to reduce the resources that the government needs to invest in chemical enterprise safety regulation to improve the overall efficiency of safety regulation. However, the study found that the cost of rent-seeking in chemical enterprises is relatively low. When the rent-seeking payoff of the third-party regulation service agencies is high, it is difficult to achieve the established regulatory objectives. Therefore, the government regulation agencies should improve the market access threshold for third-party regulation service agencies and classify third-party regulation service agencies to promote their standardization and regularization, thus effectively avoiding chemical industry safety accidents.

However, since safety regulation of chemical enterprises is a systematic project, there are still some limitations in our study. The effective solution of this problem is the result of strategic interaction among many relevant stakeholders. However, the model in this paper only considers the interaction among government regulation agencies, chemical enterprises, and third-party regulation service agencies, and does not consider the impact of public regulation. What is more, the effect of third-party regulation service agencies in chemical enterprise safety regulation has not been quantified in this paper. Therefore, in future research, we will incorporate other stakeholders into the analytical framework, introduce the social public regulation mechanism, and analyze the safety regulation of chemical enterprises in a more comprehensive and in-depth manner.

Funding: This research received no external funding.

Acknowledgments: The author sincerely appreciates the anonymous referees and editors for their time and patience devoted to the review of this paper as well as their constructive comments and helpful suggestions.

Conflicts of Interest: The author declares no conflicts of interest.

\section{References}

1. Available online: http://www.sohu.com/a/245310145_619385 (accessed on 15 August 2019).

2. Bing, W.; Chao, W.; Genserik, R. The future of hazardous chemical safety in China: Opportunities, problems, challenges and tasks. Sci. Total Environ. 2018, 643, 1-11.

3. Li, Y.; Ping, H.; Ma, Z.H. Statistical analysis of sudden chemical leakage accidents reported in China between 2006 and 2011. Environ. Sci. Pollut. Res. 2014, 21, 5547-5553. [CrossRef]

4. Shi, S.; Cao, J.; Feng, L. Construction of a technique plan repository and evaluation system based on AHP group decision-making for emergency treatment and disposal in chemical pollution accidents. J. Hazard. Mater. 2014, 276, 200-206. [CrossRef]

5. Cao, G.; Yang, L.; Liu, L. Environmental incidents in China: Lessons from 2006 to 2015. Sci. Total Environ. 2018, 633, 1165-1172. [CrossRef]

6. Zhang, H.D.; Zheng, X.P. Characteristics of hazardous chemical accidents in China: A statistical investigation. J. Loss Prev. Process Ind. 2012, 25, 686-693. [CrossRef]

7. Silvestre, B.S.; Gimenes, F.A.P.; Neto, R.S. A sustainability paradox? Sustainable operations in the offshore oil and gas industry: The case of Petrobras. J. Clean. Prod. 2016, 142. [CrossRef]

8. Béatrix, B.; Antoni-Lluís, M.; Antònia, M. How to Integrate Risk Management in IT Settings Within Management Systems? Comparison and Integration Perspectives from ISO Standards; International Conference on Software Process Improvement and Capability Determination; Springer: Cham, Switzerland, 2016.

9. Micheli, G.J.L.; Gnoni, M.G.; De Merich, D.; Sala, G.; Rosso, A.; Tornese, F.; Piga, G.; Malorgio, B. Barriers, drivers and impact of a simplified occupational safety and health management system in micro and small enterprises. Adv. Intell. Syst. Comput. 2019, 791, 81-90. 
10. Domingues, P.; Sampaio, P.; Arezes, P. Integrated Management Systems Assessment: A maturity model proposal. J. Clean. Prod. 2016, 124, 164-174. [CrossRef]

11. Zhao, J.; Suikkanen, J.; Wood, M. Lessons learned for process safety management in China. J. Loss Prev. Process Ind. 2014, 29, 170-176. [CrossRef]

12. Chen, C.W.; Liu, F.R.; Tseng, C.P. Hazard management and risk design by optimal statistical analysis. Nat. Hazards 2012, 64, 1707-1716. [CrossRef]

13. Nivolianitou, Z.; Konstandinidou, M.; Michalis, C. Statistical analysis of major accidents in petrochemical industry notified to the major accident reporting system (MARS). J. Hazard. Mater. 2006, 137, 1-7. [CrossRef] [PubMed]

14. Haviland, A.; Burns, R.; Gray, W. What kinds of injuries do OSHA inspections prevent. J. Saf. Res. 2010, 41, 339-345. [CrossRef] [PubMed]

15. Huang, L.J.; Liang, D. Development of Safety Regulation and Management System in Energy Industry of China: Comparative and Case Study Perspectives. Procedia Eng. 2013, 52, 165-170. [CrossRef]

16. Chen, J.K.C.; Zorigt, D. Managing occupational health and safety in the mining industry. J. Bus. Res. 2013, 66, 2321-2331. [CrossRef]

17. Wachter, J.K.; Yorio, P.L. A system of safety management practices and worker engagement for reducing and preventing accidents: An empirical and theoretical investigation. Accid. Anal. Prev. 2014, 68, 117-130. [CrossRef] [PubMed]

18. Makin, A.M.; Winder, C. A new conceptual framework to improve the application of occupational health and safety management systems. Saf. Sci. 2008, 46, 935-948. [CrossRef]

19. Clemons, E.K.; Madhani, N. Regulation of Digital Businesses with Natural Monopolies or Third-Party Payment Business Models: Antitrust Lessons from the Analysis of Google. J. Manag. Inf. Syst. 2010, 27, 43-80. [CrossRef]

20. Smith, P.M.; Saunders, R.; Lifshen, M. The development of a conceptual model and self-reported measure of occupational health and safety vulnerability. Accid. Anal. Prev. 2015, 82, 234-243. [CrossRef]

21. Cadman, T. Evaluating the Quality and Legitimacy of Global Governance: A Theoretical and Analytical Approach. Int. J. Soc. Qual. 2012, 2, 4-23. [CrossRef]

22. Deaton, B.J. A theoretical framework for examining the role of third-party certifiers. Food Control 2004, 15, 619. [CrossRef]

23. Hatanaka, M.; Bain, C.; Busch, L. Third-party certification in the global agrifood system. Food Policy 2005, 30, 354-369. [CrossRef]

24. Monteiro, D.S.; Anders, S. Third-party certification, food standards and quality assurance in supply chains. J. Chain Netw. Sci. 2009, 9, 83-88. [CrossRef]

25. Zhang, G.; Gao, W.; Guan, X. Evolutionary game model of food safety supervision based on the third-party intendance. J. Syst. Eng. 2015, 30, 153-164.

26. Yu, T.; Liu, C. The Analysis of Evolution Game Model and Simulation between Governments and the Third-Party in Product Quality Regulation. J. Manag. Sci. 2016, 24, 90-96.

27. Reniers, G.; Pavlova, Y. Game-Theory for Safety and Security in the Chemical Industry; Springer: London, UK, 2010.

28. Russell, D.; Simpson, J. Emergency planning and preparedness for the deliberate release of toxic industrial chemicals. Clin. Toxicol. 2010, 48, 171-176. [CrossRef] [PubMed]

29. Shen, B.; Mei, Q.; Liu, S. A study on regulating enterprise safety production based on signaling model. J. Syst. Manag. 2011, 20, 276-286.

30. Zhang, Y.; Sun, S. Research on safety production management mechanism in enterprise based on stackelberg game model. China J. Manag. Sci. 2016, 24, 159-168.

31. Shen, H.; Peng, Y.; Guo, C. Analysis of the Evolution Game of Construction and Demolition Waste Recycling Behavior Based on Prospect Theory under Environmental Regulation. Int. J. Environ. Res. Public Health 2018, 15, 1518. [CrossRef]

32. Zhu, G.; Liu, H.; Feng, M. An Evolutionary Game-Theoretic Approach for Assessing Privacy Protection in mHealth Systems. Int. J. Environ. Res. Public Health 2018, 15, 2196. [CrossRef] [PubMed]

33. Cheung, M.; Zhuang, J. Regulation Games Between Government and Competing Companies: Oil Spills and Other Disasters. Decis. Anal. 2012, 9, 156-164. [CrossRef] 
34. Yuan, B.; He, L.; Gu, B. The Evolutionary Game Theoretic Analysis for Emission Reduction and Promotion in Low-Carbon Supply Chains. Appl. Sci. 2018, 8. [CrossRef]

35. Zhu, G.; Pan, G.; Zhang, W. Evolutionary Game Theoretic Analysis of Low Carbon Investment in Supply Chains under Governmental Subsidies. Int. J. Environ. Res. Public Health 2018, 15, 2465. [CrossRef] [PubMed]

36. Shan, H.; Yang, J.; Wei, G. Industrial Symbiosis Systems: Promoting Carbon Emission Reduction Activities. Int. J. Environ. Res. Public Health 2019, 16, 1093. [CrossRef] [PubMed]

37. Smith, J.M.; Price, G.R. The Logic of Animal Conflict. Nature 1973, 246, 15-18. [CrossRef]

38. Binmore, K.G.; Samuelson, L.; Vaughan, R. Musical Chairs: Modeling Noisy Evolution. Games Econ. Behav. 1995, 11, 1-35. [CrossRef]

39. Sethi, R. Strategy-Specific Barriers to Learning and Nonmonotonic Selection Dynamics. Games Econ. Behav. 1998, 23, 284-304. [CrossRef]

40. Friedman, D. On economic applications of evolutionary game theory. J. Evol. Econ. 1998, 8, 15-43. [CrossRef]

41. Sun, Z.; Wang, M.; Zhang, W. How Can We Improve the Transformation Success Rate of Research Results in the Pharmaceutical Industry? The Game Theoretic Model of Technology Transfer Subjects. Int. J. Environ. Res. Public Health 2019, 16, 1588. [CrossRef]

42. Guo, D.; Chen, H.; Long, R. What Role Should Government Play in the Personal Carbon Trading Market: Motivator or Punisher? Int. J. Environ. Res. Public Health 2019, 16, 1905. [CrossRef]

43. Yu, K.; Zhou, L.; Cao, Q. Evolutionary Game Research on Symmetry of Workers' Behavior in Coal Mine Enterprises. Symmetry 2019, 11. [CrossRef]

44. Shen, B. Study on Safety Production Supervision Effect Based on Evolutionary Game Theory. Ind. Saf. Environ. Prot. 2013, 39, 68-70.

45. Liu, S.; Xv, J.; Mei, Q. Evolution and supervision of the production safety behavior of enterprise in industrial cluster. Ind. Eng. Manag. 2016, 21, 52-59.

46. Pi, Z.; Gao, X.; Chen, L. The New Path to Improve Construction Safety Performance in China: An Evolutionary Game Theoretic Approach. Int. J. Environ. Res. Public Health 2019, 16, 2443. [CrossRef] [PubMed]

47. Morgenstern, O.; Von Neumann, J. Theory of Games and Economic Behavior; Princeton University Press: Princeton, NJ, USA, 1953.

48. Nash, J.F. The bargaining problem. Econometrica 1950, 18, 155-162. [CrossRef]

49. Binmore, K. Modeling Rational Players: Part I. Econ. Philos. 1987, 3, 179. [CrossRef]

50. Taylor, P.D.; Jonker, L.B. Evolutionarily Stable Strategies and Game Dynamics. Math. Biosci. 1978, 40, $145-156$. [CrossRef]

51. Forrester, J.W. Industrial Dynamics. J. Oper. Res. Soc. 1997, 48, 1037-1041. [CrossRef]

52. Rashwan, W.; Abo-Hamad, W.; Arisha, A. A system dynamics view of the acute bed blockage problem in the Irish healthcare system. Eur. J. Oper. Res. 2015, 247, 276-293. [CrossRef] 